NBER WORKING PAPER SERIES

\title{
MISPRICED INDEX OPTION PORTFOLIOS
}

\author{
George M. Constantinides \\ Michal Czerwonko \\ Stylianos Perrakis
}

Working Paper 23708

http://www.nber.org/papers/w23708

\author{
NATIONAL BUREAU OF ECONOMIC RESEARCH \\ 1050 Massachusetts Avenue \\ Cambridge, MA 02138 \\ August 2017
}

We thank Giovanni Barone-Adesi, Brendan Beare, Jens Jackwerth, Carlo Sala, conference participants, and our colleagues for their constructive feedback. Constantinides acknowledges financial support from the Center for Research in Security prices, the University of Chicago and as trustee/director of the DFA group of funds, SW7 Holdings, Cook County Illinois Investment Policy Committee, and as member of the advisory board of FTSE Russell. Czerwonko and Perrakis acknowledge financial support from the Social Sciences and Humanities Research Council of Canada. The views expressed herein are those of the authors and do not necessarily reflect the views of the National Bureau of Economic Research.

NBER working papers are circulated for discussion and comment purposes. They have not been peer-reviewed or been subject to the review by the NBER Board of Directors that accompanies official NBER publications.

(C) 2017 by George M. Constantinides, Michal Czerwonko, and Stylianos Perrakis. All rights reserved. Short sections of text, not to exceed two paragraphs, may be quoted without explicit permission provided that full credit, including ()$^{\text {notice, }}$ is given to the source. 
Mispriced Index Option Portfolios

George M. Constantinides, Michal Czerwonko, and Stylianos Perrakis

NBER Working Paper No. 23708

August 2017

JEL No. G10,G11,G13,G23

\section{ABSTRACT}

The optimal portfolio of a utility-maximizing investor trading in the S\&P 500 index and cash, subject to proportional transaction costs, becomes stochastically dominated when overlaid with a zero-net-cost portfolio of S\&P 500 options bought at their ask and written at their bid price in most months over 1990-2013. Dominance is prevalent when the ATM-IV is high, right skew is low, and option maturity is short. The portfolios include mostly calls and positions are overwhelmingly short. Similar results obtain with options on the CAC and DAX indices. The results are explained neither by priced factors nor a non-monotonic stochastic discount factor.

George M. Constantinides

The University of Chicago

Booth School of Business

5807 South Woodlawn Avenue

Chicago, IL 60637

and NBER

gmc@ChicagoBooth.edu

Michal Czerwonko

McGill University

michalc04@gmail.com
Stylianos Perrakis

Department of Finance

Concordia University

1455 de Maisonneuve Bvd. West.

Quebec, Canada H3G 1M8

SPerrakis@jmsb.concordia.ca 


\section{Introduction}

We consider an investor who trades at 28-, 14-, or seven-day intervals in the S\&P 500 index and a risk free bond, subject to proportional transaction costs. The investor maximizes the expectation of her increasing and concave utility function of cash wealth at the end of the trading interval. We then consider overlaying on this portfolio a zero-net-cost portfolio, the Option Trading or OT portfolio, consisting of long and short positions in any number of European-style call and put options on the index and borrowing or lending at the risk free rate. We account for transaction costs in the trading of options by buying the options at their ask price and selling them at their bid price.

We apply standard results of stochastic dominance and state sufficient conditions under which the investor's portfolio, overlaid with the zero-net-cost portfolio, stochastically dominates the investor's original portfolio. These conditions apply irrespective of the investor's initial wealth and utility function. An intuitive interpretation of stochastic dominance is that the investor increases her expected utility by shifting income from states where the index level is high to states where the index level is low at zero net cost while maintaining the same or higher expected portfolio return.

In almost every month from 1990 to 2013 we identify zero-net-cost portfolios that potentially imply stochastic dominance, using only information available at the time that the portfolio is formed. For each date the set of admissible portfolios is derived by a numerical algorithm presented in the appendix for which the total payoff is non-negative at low values of the index support, intersects the support at a single value, becomes non-positive at high values, and has a positive expectation. The optimal portfolio is selected from the set by maximizing a given criterion. The resulting portfolios are of variable composition and contain both call and put options with either 28 days, or 14 days, or seven days to maturity. Using realized returns we then verify by out-of-sample tests that do not depend on the selection criteria that the identified portfolios would have increased, on average, the utility of any risk-averse investor holding the underlying index and the risk free asset. The results are stronger for shorter maturity options than for their longer term counterparts both in terms of profitability and the significance of the stochastic dominance tests. As a robustness check we repeat our tests using options on the CAC and DAX indices and obtain similar results. 
It is important to note that the out-of-sample stochastic dominance tests do not depend on the portfolio selection criteria that establish in-sample stochastic dominance. The stochastic dominance test compares two time series drawn from two different distributions and examines the null of non-dominance. The only requirement is that the observations be serially uncorrelated, a requirement that is verified for all the series used in our tests.

Stochastic dominance is prevalent when the at-the-money (ATM) implied volatility (IV) is high and/or the right skew is low. Although most options in the portfolios are out-of-the money (OTM), more than $37 \%$ of the cross-sections contain in-the-money (ITM) calls and more than 32\% ITM puts. The portfolios include more than double the number of calls than puts and the call positions are overwhelmingly short positions, consistent with the practice of writing covered calls. This contradicts the common belief that puts but not calls are overvalued, which was established in a frictionless context and is discussed further on in this section. ${ }^{1}$

During the 2008 to 2009 financial crisis the majority of portfolio positions are net short put positions. We interpret this finding as investor overreaction to the crisis in the form of inflated put prices. Furthermore we find that the option portfolio composition depends on characteristics of the projected index distribution. We also refute the conjecture that the OT portfolios primarily consist of long positions in options with IV below the IV smile and short positions in options with IV above the IV smile: such options constitute a small component of the OT portfolio. We conclude that at least some S\&P 500 call and put options may be significantly mispriced relative to the index. This potential mispricing is qualitatively different from other anomalous results such as overpriced straddles in earlier studies, all of which were studied in a frictionless economy. ${ }^{2}$ In our case the mispriced portfolios correspond to a tradable anomaly insofar as an investor holding an index-tracking tradable fund such as a SPDR can costlessly increase her returns without incurring additional risk.

Stochastic dominance tests are subject to the criticism that they are based on the maintained hypothesis that the index return is the only priced factor and the stochastic discount factor is monotone decreasing in the index return. Without relying on this maintained hypothesis we test whether the excess returns of the OT portfolios are rewards for risks other than market risk. To

\footnotetext{
${ }^{1}$ See Bondarenko (2014) and Driessen and Maenhout (2007).

${ }^{2}$ See Broadie, Chernov, and Johannes (2007, 2009).
} 
this end we adjust the excess returns with the three factors in Fama and French (1993) and the factors “Jump", "Volatility Jump", "Volatility", and "Liquidity” in Constantinides, Jackwerth, and Savov (2013). In all cases we find that the excess returns of the OT portfolios remain positive and statistically significant.

Finally we test whether a $U$-shaped stochastic discount factor chosen from the observed index and option prices nullifies our stochastic dominance results in a frictionless setting. Given the wide variety of models and empirical estimates of the stochastic discount factor and the dependence of their results on the unobservable frictionless option prices, we choose the only model for which an explicit expression for the stochastic discount factor involving observable ex post random variables is available, the Christoffersen, Heston, and Jacobs (2013) GARCH-based extension of the Heston and Nandi (2000) model. We extract the parameters of the $P$ distribution from index returns and the missing single parameter that maps the $P$ distribution into the $Q$ distribution from the option market by trading at the midpoint of each option's bid-ask spread. ${ }^{3}$ We find that the risk-adjusted OT portfolio excess returns are even higher than the unadjusted returns while the returns for the OT portfolios based on model prices lie outside the confidence intervals bootstrapped around observed market prices. We conclude that the high OT portfolio excess returns are not rewards for risk reflected in this particular $U$-shaped stochastic discount factor, while the options entering the OT portfolios are mispriced with respect to their universe as reflected in the stochastic discount factor extracted from it.

Our paper builds on several strands of the options literature. It builds on the literature that invokes the absence of stochastic dominance in a frictionless economy. ${ }^{4}$ It also builds on the literature that invokes the absence of stochastic dominance in an economy with frictions. Constantinides and Perrakis $(2002,2007)$ derive bounds on option prices under proportional transaction costs such that a violation of these bounds implies stochastic dominance for any riskaverse investor. Constantinides, Jackwerth, and Perrakis (2009) identify in-sample violations of these bounds for European S\&P 500 options. Constantinides, Czerwonko, Jackwerth, and Perrakis (2011) identify similar in-sample violations of the call upper bound on American S\&P 500 futures

\footnotetext{
${ }^{3}$ We do not impose put-call parity in the OT options, which is routinely applied in the frictionless models even though it does not hold at the bid-ask spread midpoint. Parity, as well as "smoothing" of the data, is imposed in estimating the missing parameter, following standard practice in the frictionless asset pricing literature.

${ }^{4}$ See Levy (1985), Oancea and Perrakis (2014), Perrakis and Ryan (1984), and Ritchken (1985).
} 
options in about one-third of the sample months. They use a zero-net-cost portfolio to exploit these violations, apply the statistical tests of Davidson (2009) and Davidson and Duclos (2013) to the realized returns of the index and the option, and verify that the modified portfolio stochastically dominates the original portfolio over the entire time series of returns. This extension of the literature is, to our knowledge, the only available approach for pricing options in the presence of transaction costs. ${ }^{5}$

The key difference between the earlier results and the current paper is that we allow the investor to include options of different type, long and short calls and puts of different moneyness in a zero-net-cost portfolio, not just one type of options. We identify the set of portfolios that imply stochastic dominance and use different criteria to select the "best" portfolio from the set. This allows us to identify mispricing of options in almost every sample month, as opposed to the earlier results that allow for only one type of options, short calls violating a given criterion, in the zeronet-cost portfolio, and identify mispricing only in approximately one-third of the sample months. Furthermore the gain achieved by the investor by holding our new zero-net-cost portfolios is major, especially for the shorter maturity options, since it not only reduces the risk of the index but also increases the realized return by about $2 \%$ annually. Note that this expected realized return equals $50 \%$ of the assumed cum-dividend expected return on the index in excess of the risk free rate.

In robustness checks we address whether our search for mispriced options exhausts the options that produce dominating OT portfolios by removing from each cross-section the options that are included in the optimal portfolio - the "first pass" options - and repeating the search with the remaining options in the cross-section. We still find stochastic dominance violations but the results are statistically weaker. We also rule out the possibility that the observed higher mean return of the OT portfolios over the IT portfolios is attained by the OT investor's buying options that lie below the IV skew and writing options that lie above it. Finally we verify that the profitability of the OT portfolios appears because they contain elements from both calls and puts, both long and short positions and both OTM and ITM options, since the profitability and number of feasible dates decrease once any one type of these options is removed from the choice set. The portfolios cannot be explained by call or put butterflies or vertical spreads and are not an extension

\footnotetext{
${ }^{5}$ For the failure of traditional no-arbitrage approaches in the presence of proportional transaction costs see Perrakis and Lefoll (2004) and Soner, Shreve, and Cvitanic (1995).
} 
of the profitable covered calls identified in Constantinides, Czerwonko, Jackwerth, and Perrakis (2011).

Our results also relate to the literature that attempts to reconcile the underlying $P$ distribution of returns extracted from observed returns with the risk neutral $Q$ distribution extracted from option prices which are implicitly assumed to be "correctly" priced. Since frictionless option prices are unobservable the extraction of the $Q$ distribution is subject to both model and estimation errors. ${ }^{6}$ These sources of errors probably account for the widely varying estimates of the parameters required to reconcile the $P$ and $Q$ distributions. ${ }^{7}$

We concentrate on a particular subset of such frictionless asset pricing models which test a key assumption of the stochastic dominance approach, that the stochastic discount factor is nonincreasing in wealth for at least a subset of investors that hold only the index portfolio and the risk free asset. Ait-Sahalia and Lo (2000) and Jackwerth (2000) estimate a non-monotonic stochastic discount factor for the index option market - the stochastic discount factor puzzle. Nonmonotonicity is rationalized with stylized models of frictionless economies based on estimates from the reconciliation of the $P$ and $Q$ distributions by Bakshi, Madan, and Panayotov (2010), Chabi-Yo, Garcia, and Renault (2008), and Christoffersen, Heston, and Jacobs (2013). BaroneAdesi, Dall'O, and Vovchak (2012), Barone-Adesi, Engle, and Mancini (2008), Beare (2011), and Beare and Schmidt (2016) test the non-monotonicity of the stochastic discount factor.

The existence of a locally increasing stochastic discount factor may imply the existence of an option portfolio dominating the index in the frictionless world but does not justify market inefficiencies such as the tradable anomaly corresponding to our portfolios. We verify here whether our OT portfolios are "correctly" priced in a frictionless world by concentrating on the particular type of non-monotonicity that involves a $U$-shaped stochastic discount factor increasing in the high range of index returns. Since our zero net cost OT portfolios have negative payoffs at the high return range, such a $U$-shaped stochastic discount factor is the most likely to generate a

\footnotetext{
${ }^{6}$ See Rubinstein (1985, p. 465).

${ }^{7}$ See Bliss and Panigirtzoglou (2004), Eraker, Johannes, and Polson (2003), Rosenberg and Engle (2002), and Ziegler (2007).
} 
"correct" value for them, namely a value that is not significantly different from zero. ${ }^{8}$ It is on this basis that we conclude that the OT portfolios are mispriced in a frictionless world.

Another strand of the literature addresses the option traders' and intermediaries' credit constraints and funding liquidity. Bates (2003) points out the inconsistency of the representative investor assumption with the actual operations of option markets in hedging operations involving crash risk, as well as the inability of models to combine transaction costs with no arbitrage. Bollen and Whaley (2004), Bondarenko (2014), and Garleanu, Pedersen, and Poteshman (2009) study the effect of the buying pressure on index put options. Chen, Joslin, and Ni (2016) and Constantinides and Lian (2016) study the joint effect of the buying and selling pressure on index put options.

In our final robustness check we apply our portfolio selection algorithm to the universe of frictionless options as defined in most studies by using only the OTM call and put bid-ask spread midpoints. The prices of the ITM options are then derived by applying the put-call parity. In such a universe of options the OT portfolios have again strongly significant average payoffs with low volatilities and high Sharpe ratios, but have very different compositions. The short calls that used to predominate are now a small fraction of the portfolios and are replaced by short puts and large short positions in the index. These results offer a partial explanation of the alleged put overvaluation in the frictionless economy observed in earlier studies which, however, disappears under realistic trading conditions.

The paper is organised as follows. We present the theory of stochastic dominance in Section 2. We discuss the data in Section 3 and the empirical methodology in Section 4. The main empirical results are presented in Section 5. In Section 6 we address the relation between stochastic dominance and the smile. In Section 7 we investigate the characteristics of the dominating portfolios and the options that are included in them and conduct a number of robustness tests. Section 8 examines whether various priced factors or a $U$-shaped stochastic discount factor explain our results. In Section 9 we present similar results based on options on the CAC and DAX indices. We conclude in Section 10.

\footnotetext{
${ }^{8}$ By contrast, non-monotonicity at the left tail, such as the one occasionally observed in the Barone-Adesi, Engle and Mancini (2008, figure 5) results, will, if anything, increase the value of the OT portfolios relative to their expected returns under the P-distribution.
} 


\section{Stochastically Dominating Portfolios}

We consider an investor who trades at discrete dates 28 , or 14 , or seven days apart, $t=0,1, \ldots, T$, in an index portfolio and a risk free asset (cash), subject to proportional transaction costs for the index. We denote the index price at date $t$ by $S_{t}$. At the terminal date, $T$, the wealth is converted into cash, net of transaction costs. The investor maximizes the expectation of her utility of terminal cash wealth. We assume that the utility function is von Neumann-Morgenstern, strictly increasing, and concave. We denote by $V\left(x_{t}, y_{t}, t\right)$ the value function (indirect utility) at date $t, t \leq T$, where $\left(x_{t}, y_{t}\right)$ denote the holdings in the cash and index accounts, respectively. We assume that the equity premium is positive so that the investor optimally invests a non-negative amount in the index portfolio at each date.

Constantinides (1979) addresses this problem under general conditions and proves two properties which are useful for the problem at hand. First he proves that $V\left(x_{t}, y_{t}, t\right)$ is strictly increasing and concave in $\left(x_{t}, y_{t}\right)$. This implies that the marginal utility of the value function with respect to the index account, $V_{y}\left(x_{t}, y_{t}, t\right)$, is monotone decreasing in $y_{t}$ at any date $t, t \leq T$. Second he proves that there exists a region of no-transactions such that the investor refrains from transacting at date $t$ if the portfolio holdings lie in it. In the special case of constant relative risk aversion this region is a cone, with no transactions if $\underline{\lambda}_{t} \leq y_{t} / x_{t} \leq \bar{\lambda}_{t}$. Constantinides (1986) shows that the no-transactions region is wide even for a very small transactions cost rate and the investor refrains from trading most of the time in the sense that the utility losses from not adjusting the portfolio to its frictionless optimal proportions are low for all realistic parameter values.

For our purposes we do not make the limiting assumption that the relative risk aversion is constant or the dynamics are limited to diffusion. Nevertheless we assume that an investor who starts at the beginning of the month somewhere in the middle of the no-transactions region optimally refrains from trading in the short time span of 28 , or 14 , or seven days. Note that even if the investor refrains from trading for longer periods such as several months our results remain approximately correct since the width of the no-transactions region stipulates little trading. ${ }^{9}$

\footnotetext{
${ }^{9}$ We verify this using the numerical approach of Czerwonko and Perrakis (2016) which assumes a constant relative risk aversion investor, jump diffusion asset dynamics, and a finite fixed horizon. The observed intermediate trading in numerical simulations under all realistic parameter values is insignificant even for a two-year horizon.
} 
Combined with the first result that $V_{y}\left(x_{t}, y_{t}, t\right)$ is monotone decreasing in $y_{t}$ and the fact that the investor has a positive investment in the index, we conclude that $V_{y}\left(x_{t+1}, y_{t+1}, t+1\right)$ is monotone decreasing in the stock price, $S_{t+1}$.

We consider a zero-net-cost portfolio at date zero consisting of $J$ European-style call and put options on the index with 28 days to expiration, and borrowing or lending at the risk free rate. We also consider zero-net-cost portfolios with options 14 days or seven days to expiration. The options are bought at their ask price and written at their bid price.

Let $A\left(S_{t}\right)$ denote the payoff of the zero-net-cost portfolio at date $t$, where the net cash flow of the portfolio is converted into units of the index account, net of transaction costs. If

$$
E_{t}\left[A\left(S_{t+1}\right) V_{y}\left(x_{t+1}, y_{t+1}, t+1\right)\right]>0,
$$

then the investor increases her utility by overlaying this zero-net-cost portfolio over her original investment in the index and the risk free asset. The following lemma provides sufficient conditions for equation (1) to hold.

Lemma: A sufficient condition for equation (1) to hold is that (a) $E_{t}\left[A\left(S_{t+1}\right)\right] \geq 0$ and (b) there exists a number $\hat{S}$ such that $A\left(S_{t+1}\right)>0$ for $S_{t+1} \leq \hat{S}$ and $A\left(S_{t+1}\right) \leq 0$ for $S_{t+1}>\hat{S}$.

To see this, note that conditions (a) and (b) imply

$$
\begin{aligned}
& E_{t}\left[A\left(S_{t+1}\right) V_{y}\left(x_{t+1}, y_{t+1}, t+1\right)\right] \\
& \left.>E_{t}\left[A\left(S_{t+1}\right)\right]\right] E\left[\left\{V_{y}\left(x_{t+1}, y_{t+1}, t+1\right)\right\}_{S_{t+1}=\hat{S}}\right] \\
& \text { (because } \left.V_{y}\left(x_{t+1}, y_{t+1}, t+1\right) \text { is decreasing in } S_{t+1} \text { and } A\left(S_{t+1}\right)>\leq 0 \text { as } S_{t+1} \leq>\hat{S}\right) \\
& >0
\end{aligned}
$$

This completes the proof. Note that, for an investor with linear utility, $V_{y}\left(x_{t+1}, y_{t+1}, t+1\right)$ is a positive constant and inequality (1) implies that $E_{t}\left[A\left(S_{t+1}\right)\right] \geq 0$. The lemma states that when $A\left(S_{t}\right)$ has the shape indicated by condition (b) then condition (a) is necessary for stochastic dominance. Intuitively, for the chosen shape of $A\left(S_{t}\right)$, an increase in the utility of the risk neutral investor implies an increase in the utility of all risk averse investors. In Section 4 we describe the construction of zero-net-cost portfolios that satisfy the sufficient conditions of the lemma. 


\section{Description of the Data}

The main empirical results are based on monthly and weekly options on the S\&P 500 index. We obtain prices of monthly S\&P 500 European puts and calls 28, 14, and seven days to maturity from the Chicago Board Options Exchange (CBOE) tape with intraday quotes from January 1990 to February 2013, yielding 278 dates. ${ }^{10}$ The 14-day options are the same 28-day options with respect to moneyness and expiration date but observed 14 days to expiration. The seven-day options are the same 28-day options with respect to moneyness and expiration date but observed seven days to expiration. We also present results over the shorter time period in which weekly options are traded. For robustness we replicate our results on the French CAC and German DAX indices for which we use OptionMetrics data with end-of-day prices for their European options. ${ }^{11}$

We delete obvious data entry errors such as multiple or missing data or bid prices exceeding ask prices. We filter the data by checking that the put-call parity and convexity with respect to the strike price under transaction costs in the index and bid-ask prices of options hold. We conservatively use ten basis points as a one-way transactions cost rate for index trades. ${ }^{12} \mathrm{We}$ also apply liquidity filters to guarantee that only options that can be traded under realistic conditions enter our choice set. We include call prices with bid prices at least 15 cents and moneyness within 0.96-1.08. For put options we discard all options more than $4 \%$ in the money but admit all options with bid prices of at least 15 cents. This asymmetry in admitting put options is justified by the relatively higher liquidity of OTM puts. Lastly we only admit quotes updated within the past 15 minutes. After applying our filters we exclude four dates on which we cannot find at least three call options and three put options available for selection in our portfolios.

In Table 1 we display statistics on the average number of 28-, 14-, and seven-day S\&P 500 options that pass the filters each month and are available for inclusion in the zero-net-cost portfolios. In general the market for puts is more liquid than the market for calls and, therefore, the number of puts that pass the filters exceeds the number of calls. In the years 2000 and 2004 the

\footnotetext{
${ }^{10}$ Unreported results for 21-day options are generally similar to the ones for 28-day options.

11 Other optioned indices such as EURO STOXX 50 and FTSE are eliminated either because of lack of data or settlement terms that make the results non-comparable to our base case.

12 Note that the lower this rate the more arbitrage violations are found. With no transaction costs for the index and with trading in options at the bid-ask midpoint virtually all options prices are rejected because of arbitrage violations; see also Ioffe and Prisman (2013).
} 
CBOE increased the quote update frequency and the number of strikes at which options are traded generally increased with the index level given a relatively constant increment between pairs of adjacent strikes. As a result the average number of options that pass the filters doubles after 2004. We take these changes into account when we report the results on the stochastic dominance tests and when we describe the characteristics of the options that are frequently included in the zeronet-cost portfolios. The table also describes the average number of options included in these portfolios.

\section{[Table 1 here]}

We build the zero-net-cost portfolios at 3:00 PM SET, one hour before market closing, thus avoiding possible distortions of the closing market inherent in end-of-day prices. We execute the trades 15 minutes later for these same options which are found to be optimal to include in the portfolio, readjusting their weights with the same objective as at the 3 PM portfolio derivation time for the data observed one minute before the actual trade. For a limited number of options in the optimal portfolios this additional derivation takes a few hundredths of a second, thus leading to little if any distortion due to the additional trade execution time. Since SPX options are exercised at the opening price of the terminal date we collect the exercise proceeds by using the opening value of the index and ascribe the proceeds to the ending position of the index.

We derive the index price from the cost-of-carry relation between the observed spot index and its nearest-to-maturity futures contract as follows. We use a data set from Tick Data. We estimate the implied index price by recording implicit cost-of-carry coefficients from observed spot-futures pairs for one hour before our estimation or trade time in one-minute intervals. We then use the median value of this coefficient to convert the most recent futures value into the implied spot index price. Note that as of 2006 the increased quality of reporting of the index price renders the difference between the cash index and its derived price negligible. We derive the dividend yield by using cash daily payouts obtained from Standard and Poor. For the interest rate we use the three-month constant maturity T-bill rate obtained from the Federal Reserve Economic Data. Finally we assume a one-way transaction costs rate of $0.25 \%$.

For our base case results we model the index price as lognormally distributed with average cum dividend return equal to $4 \%$, plus the annualized risk free rate, as per the long-term historical average. In the robustness Section 9 we use $2 \%$ and $6 \%$, plus the annualized risk free rate, as the 
cum dividend index return and obtain virtually identical results. We forecast the index return volatility till the expiration date by using the CBOE VIX volatility adjusted by the mean forecast difference between the VIX and the realized volatility for the period 1986 to the current date; both the VIX and the realized volatility of daily returns are measured in four-week intervals without overlap, with the latter quantity defined as the square root of 252 times the mean squared daily return. ${ }^{13}$ The amount by which the VIX exceeds the realized volatility (the negative volatility risk premium) is relatively stable over time, about $4.5-4.8 \%$.

There are fewer options available for our robustness checks with the CAC and DAX indices. Although closing prices are available from January 2002 for DAX and April 2004 for CAC, bid and ask option prices for both indices exist only since 2006. We use the data set which contains bid and ask prices to construct the trades and both data sets to construct the volatility projections. In constructing our portfolios we use the data from January 2006 to February 2013, with the latter date corresponding to the end of our S\&P 500 data. This results in 86 potential dates for options maturing on the third Friday of each month, reduced to about 80 dates due to data availability and our requirement of choosing from at least three call and put options after deletions due to violations of the no arbitrage conditions. For the latter we use the same approach and $0.1 \%$ transaction cost rate as in the S\&P 500 options. Since the resulting sample has less than one third of the 278 dates available for the full sample of S\&P 500 options, we also present results with the January 2006 to February 2013 S\&P 500 data to maintain comparability between indices.

Since we only have end-of-day data for the CAC and DAX indices we derive the dividend adjustment for the index price as follows. We record all put-call pairs within the moneyness range of 0.98-1.02 and for each pair we derive the adjustment for the index price which makes the putcall parity hold exactly with the use of bid-ask midpoint option prices, if available, and last prices, otherwise. The median value of these adjustments becomes the final dividend adjustment for the

\footnotetext{
${ }^{13}$ Because of the importance of the measurement of this gap in identifying in-sample mispricing, we use two additional variants of the VIX forecast, both in terms of the logarithm of the squared VIX. In the first variant we measure the average difference between this quantity and a similar quantity for realized returns as above. In the second variant, we regress this quantity for realized returns against a similar one for VIX and at the trading date we apply our estimates to the previous day closing value of VIX to form a forecast. In this last variant we also vary the length of the rolling window used to estimate the regression coefficients. The out-of-sample tests are independent of the index return volatility choice and all of the choices produce very similar out-of-sample results.
} 
closing price of the index. Similarly the median IV of these inferred put-call parities is used as the ATM IV for the corresponding day.

Our volatility projections differ for the CAC and DAX indices. For CAC we use the ATM IV to form our projections since it introduced its volatility index only in 2011. With this ATM IV we record the projection errors for all dates preceding a given trading date and subtract the average error from the observed ATM IV for this given date, an adjustment typically of the order of $2.5 \%$. For DAX we use the ATM IV for the period preceding the introduction of the DAX volatility index (VDAX) in October 2005 and the VDAX index thereafter; in practice, our ATM IV estimates are very similar to the VDAX. As for S\&P 500 and CAC we adjust the VDAX for the projection errors, typically of the order of $1 \%$. These adjustments for CAC and DAX differ from the typical adjustment for S\&P 500 by about 5\% for the same period from January 2006 to February 2013.

\section{$4 \quad$ Empirical Methodology}

We denote by IT (index trader) the investor who holds an optimal portfolio of the index and cash and by OT (option trader) the investor who holds the same portfolio as the IT plus the zero-net-

cost portfolio with payoff $A\left(S_{t+1}\right)$ at maturity. Our empirical methodology involves two steps. In the first step, for the portfolios with options 28 days to maturity, we construct in-sample zero-netcost portfolios at dates on which we have options with 28 days to maturity. This step is independent of any assumptions about the IT investor. We follow a similar procedure to construct portfolios with options 14 and seven days to maturity. In the second step we verify out of sample the stochastic dominance (SD) of the OT investor's terminal wealth relative to the IT investor's terminal wealth by applying SD tests over the entire sample period. Based on the lemma stated in Section 2, the IT and OT comparisons are done on the basis of the time series of the corresponding index values in their portfolios at the option expiration dates.

In our base case the IT investor is an index fund holding 100,000 index units, which corresponds to approximately $\$ 150$ million in index holdings in our sample period. In this case we 
consider the scale of trading in one option per unit index as realistic. For instance, writing 0.5 calls with strike $K_{1}$ and buying 0.5 calls or puts with strike $K_{2}$ per unit index exhausts our limit. ${ }^{14}$

At the beginning of the 28-day (or 14-day or seven-day) period, $t$, we build a grid of feasible values of $\hat{S}, \hat{S}>0$, that allows us to find a zero-net-cost portfolio from among the universe of 28-day (or 14-day or seven-day) options such that the payoff $A\left(S_{t+1}\right)$ in 28 days (or 14 days or seven days) satisfies the following conditions: $A\left(S_{t+1}\right)>0$ for $0.6 S_{t} \leq S_{t+1} \leq \hat{S} ; A\left(S_{t+1}\right) \leq 0$ for $S_{t+1}>\widehat{S}$; and $E_{t}\left[A\left(S_{t+1}\right)\right]>0$. For each value of $\hat{S}$ we choose the portfolio of options that maximizes the expected payoff, $E_{t}\left[A\left(S_{t+1}\right)\right]$, subject to the conditions $A\left(S_{t+1}\right)>0$ for $0.6 S_{t} \leq S_{t+1} \leq \hat{S}$ and $A\left(S_{t+1}\right) \leq 0$ for $S_{t+1}>\hat{S}$. Thus we form a set $\Omega(\hat{S})$ of OT portfolios that ex ante stochastically dominate their IT counterparts. The procedure follows a linear programming (LP) formulation, described in detail in Appendix A.

We choose from the set $\Omega(\hat{S})$ the "best" portfolio according to a given criterion. We try several alternative criteria and find broadly consistent results in terms of the composition of this portfolio. Most importantly we demonstrate in the next section that these best OT portfolios stochastically dominate their IT counterparts using realized prices as well. As our base case criterion we pick the portfolio that maximizes the Sharpe ratio, $E_{t}\left[S_{t+1}+A\left(S_{t+1}\right)-S_{t} R\right] / s t d_{t}\left(S_{t+1}+A\left(S_{t+1}\right)\right)$. In robustness tests, we replace the maximization of the Sharpe ratio with the maximization of the gain/loss ratio, $E_{t}\left[A\left(S_{t+1}\right)^{+}\right] / E_{t}\left[-A\left(S_{t+1}\right)^{-}\right]$; or, the maximization of the Sortino ratio, $E_{t}\left[A\left(S_{t+1}\right)\right] / s t d_{t}\left(\left[S_{t+1}+A\left(S_{t+1}\right)\right]^{-}\right)$; or, simply choose the maximum feasible $\hat{S}$.

We stress that the restriction $0.6 S_{t} \leq S_{t+1} \leq \hat{S}$ is imposed on the construction of the portfolios but is not imposed on realized prices $S_{t+1}$. In unreported robustness tests we also consider the case where we allow the index to become worthless in one month, by replacing this restriction

\footnotetext{
${ }^{14}$ In unreported results we also consider trade sizes not easily available even for investors with large holdings, allowing trading for up to 1,000 options per unit index. In this case, the expected return of the OT investor is higher.
} 
with $S_{t+1} \leq \hat{S}$, and obtain similar results. We relax the lognormality assumption by including extra weight in the tails of the distribution to account for empirically observed properties of the index returns. We also consider time-varying volatility following well-known daily GARCH processes; these are discussed in our robustness tests section. The construction of these portfolios relies on information that is available at the beginning of the 28-day (or 14-day or seven-day) period.

The search for the potentially mispriced portfolios takes place on a subset of the available options within the moneyness range of the options that has already been limited by liquidity considerations according to the criteria specified in Section 2. Essentially our choice of portfolios incorporates the conditions of the Lemma at every single point of an appropriately defined lower range of the support and imposes the maximization of the expected payoff. Specifically we assume a lower support for the index generally independent of the span of a given discrete return space. In the last step we select the portfolio corresponding to the value $\widehat{S}$ that maximizes the Sharpe ratio.

We carefully distinguish the period of the financial crisis which we define as the twelve months after October 2008. In the one-month period before mid-October 2008 the index lost some $25 \%$ of its value which resulted in several unusual opportunities in the options market in the following months.

In the second phase we compare the IT and OT portfolios at the option maturity and generate two time series of realized returns. We compare the performance of the IT and OT portfolios in several ways. First we derive bootstrap p-values for a negative mean excess return. Second we apply the Davidson-Duclos (DD, 2013) test for restricted second-order stochastic dominance. This test is based on the null hypothesis of non-dominance as opposed to several other tests where the null is dominance and would provide a relatively weak evidence by finding a high $p$-value for the null since by construction they do not reject anything. DD demonstrates that the null of non-dominance cannot, in principle, be rejected over the entire joint support for the two examined prospects even if it exists in population. Therefore some points in the tails of this joint support are removed from the search for the minimal $t$-stat which forms the basis of the bootstrap procedure in the DD test. ${ }^{15}$

\footnotetext{
15 The DD test considers a minimal $t$-stat in the restricted support. If there is no restriction in the left tail, a minimal $t$ stat is equal to one by construction. Without any restriction in the right tail, the minimal $t$-stat in cases like ours will usually correspond to the difference in means, whose statistical significance is too strong a condition for SD. See also
} 
It is important to note that the out-of-sample DD tests do not depend on the portfolio selection criteria that establish in-sample stochastic dominance, namely the VIX, the mean index return, or the lognormality assumption. The DD test compares two time series drawn from two different distributions and examines the null of non-dominance. The only requirement is that the observations be serially uncorrelated, a requirement that was verified for all the series used in our DD tests. For our base case with the Sharpe selection criterion, the 28-day IT and OT portfolio returns and their difference have first-order autocorrelations -0.039 (p-value 0.515), -0.062 (pvalue 0.301 ), and -0.051 (p-value 0.396 ), respectively. The autocorrelations for the 14-day and seven-day portfolios and for the CAC and DAX indices are also statistically insignificant.

\section{Empirical Results on Stochastic Dominance}

In Table 2 we present the results over the whole sample period from 1990.01 to 2013.02 for four different portfolio selection criteria: the Sharpe ratio, the gain/loss ratio, the Sortino ratio, and the maximization of $\hat{S} . \mu$ is the mean and $\sigma_{O T-I T}$ is the volatility of the difference of the annualized percentage return between the OT and IT portfolios. In the top panel we present results for the portfolios constructed 28 days prior to the options' maturity; out of the 278 dates there are 270 dates with feasible portfolios. In the middle panel we present results for the portfolios constructed 14 days prior to the options' maturity; out of the 278 dates there are 272 dates with feasible portfolios. In the bottom panel we present results for the portfolios constructed seven days prior to the options' maturity; out of the 278 dates there are 272 dates with feasible portfolios. Statistical tests are performed on the basis of the total number of dates. The $p$-values for the difference in means are derived via bootstrap with 10,000 draws. For the DD test, 10\% trimming (deleting sequentially lowest outcomes in either return set) in the left tail is uniformly performed while similar trimming in the right tail is as shown. The results of the DD tests without trimming in the

Constantinides, Czerwonko, Jackwerth, and Perrakis (2011), where the application of the DD test in a similar situation is described in detail and for evidence that the test is conservative in rejecting a false null. 
right tail are not shown because they are qualitatively the same as the $p$-values for the difference in means.

\section{[Table 2 and figure 1 here]}

For the portfolios constructed 28 days prior to the options' maturity and for all selection criteria, the annualized mean return of the OT portfolio exceeds the mean return of the IT portfolio by about half-a-percent. With the exception of the gain/loss ratio criterion, this difference is not statistically significant at conventional levels probably because we conservatively restrict the scale of the zero-net-cost portfolio. The volatility of the annualized return of the IT portfolio is $16.48 \%$ and is higher than the volatility of the OT portfolios. In figure 1 we present the difference in returns between the OT and IT portfolios as a function of the S\&P 500 index return for 28-day and 14day options. Consistent with the objective of constructing OT portfolios that stochastically dominate the IT portfolios, the difference in returns is positive for low values of the index return and negative for high values.

For the portfolios constructed 14 days prior to the options' maturity and for all the selection criteria, the annualized mean return of the OT portfolio exceeds the mean return of the IT portfolio by well over one percent and this difference is statistically significant at conventional levels for all portfolio selection criteria with the exception of the Sharpe ratio. It is especially large and significant under the gain/loss ratio and the maximization of $\hat{S}$ criteria. The volatility of the annualized return of the IT portfolio is $17.15 \%$ and is higher than the corresponding volatility of the OT portfolios. This improvement in performance for 14-day options occurs in spite of higher proportional transaction costs, with the bid-ask spread at $8.7 \%$ on average for ATM options, compared to $6.5 \%$ for 28 -day options for similar average levels for ATM IV for both maturities. We look at possible drivers of this difference in trading results in the next section.

For the portfolios constructed seven days prior to the options' maturity and for all the selection criteria the annualized mean return of the OT portfolio exceeds the mean return of the IT portfolio by well over one percent and this difference is statistically significant at conventional levels for all portfolio selection criteria. It is especially large and significant under the gain/loss ratio and the maximization of the gain/loss ratio. The volatility of the annualized return of the IT portfolio is $18.12 \%$ and is higher than the corresponding volatility of the OT portfolios. This improvement in performance for seven-day options occurs in spite of $9.8 \%$ average ATM 
proportional spreads for seven-day options. We look at possible drivers of this difference in trading results in the next section.

In unreported tests we relax the assumption of lognormality used to derive the OT portfolios. For the underlying distribution we use an Edgeworth tree as in Rubinstein (1998), with the excess kurtosis and skewness set at 0.5 and -0.5 , respectively, roughly corresponding to the long-term empirical quantities for the S\&P 500 index. The increased accuracy in approximating the underlying distribution of the index improves, as expected, the results in comparison to the ones in Table 2, but the improvement in profitability is limited to about $0.3 \%$ per annum in the most extreme case of the seven-day options. For these reasons we maintain lognormality as our base case.

The formal tests of stochastic dominance resoundly reject the null hypothesis of nondominance for the 28-day, 14-day, and seven-day portfolios and for all portfolio selection criteria with the weakest results for 28-day options for which the null is rejected only at 5\% significance for $5 \%$ trimming in the right tail. In the 28 -day option portfolios the dominance is achieved by keeping the same mean as IT but reducing risk by shifting weight to the low return states, while in most 14-day and seven-day portfolios the mean return significantly increases as well.

Note that the flexibility in portfolio choice achieved by the approach used in this paper finds dominating portfolios for almost all cross-sections. In contrast, Constantinides, Czerwonko, Jackwerth, and Perrakis (2011) identify OT dominance in only about one-third to one-half of the sample months. We conclude that the 28-day, 14-day, and seven-day OT portfolios stochastically dominate their IT counterparts. Furthermore this conclusion is robust to all portfolio selection criteria.

These results remain basically unchanged when we drop the restriction on the maximal loss and allow the index to become worthless at its lowest support. In unreported results we show that the realized returns significantly increase for all decision criteria for 28-day options and become significant at the $5 \%$ level or better for all but the gain/loss ratio. Exactly the opposite takes place for the 14-day and seven-day options, for which the results worsen and become non-significant for all but the max $\hat{S}$ criterion. The realized returns remain essentially unchanged in terms of the SD tests and show OT dominance in all cases. 
An indicator of the mispricing of each option cross-section is the Sharpe ratio of the OT portfolio. In panel A of figure 2 we present the time series of the Sharpe ratio of the OT portfolio for both the 28- and 14-day options in the case where we maximize the Sharpe ratio. The Sharpe ratio is persistent and follows the same pattern for both maturities. The similarities of the two graphs are remarkable given that they are derived two weeks apart and suggest that SD opportunities in S\&P 500 options are persistent.

Another indicator of the mispricing of each option cross-section is the annualized expected gain, $E_{t}\left[A\left(S_{t+1}\right)^{+}\right]$. In panel B of figure 2 we present the time series of the expected gain for both the 28- and 14-day options in the case where we maximize the Sharpe ratio. The expected gain is evidently less persistent and is higher for the shorter maturity portfolios.

In Table 3 we divide the option portfolios into terciles based on the expected gain, $E_{t}\left[A\left(S_{t+1}\right)^{+}\right]$. The table shows that the difference in the realized return between the OT and the IT portfolios is highest and stochastic dominance is most prevalent when the expected gain is the highest.

[Table 3 and figure 2 here]

\section{Relation between Stochastic Dominance and the Smile}

In Tables 4-6 we consider separately the stochastic dominance tests for the low and high terciles of a given smile characteristic (ATM IV, left skew, and right skew) for 28-, 14-, and seven-day options, respectively. Overall the power of the tests is diminished by the fact that we have only 92 observations in each tercile instead of 278 observations for the main results in Table 2.

[Tables 4-6 here]

For all maturity options, the mean difference of the annualized percentage return between the OT and IT portfolios $(\mu)$ is significantly higher when the ATM IV is in the high tercile of the ATM IV. The formal tests of stochastic dominance resoundly reject the null hypothesis of non- 
dominance for all maturity options and for all portfolio selection criteria. We conclude that stochastic dominance is prevalent when the ATM IV is high.

For 28-day options the mean difference of the annualized return between the IT and OT portfolios is higher when the left skew is low. For 14-day and seven-day options the mean difference of the annualized return between the OT and IT portfolios is high when the left skew is low or high with a single exception for the Sharpe ratio for 14-day options when the performance is poor when the left skew is high. We conclude that the classification of portfolios according to the steepness of the left skew does not provide consistent results.

For all maturity options the mean difference of the annualized return between the OT and IT portfolios is significantly higher when the right skew is low. In the low tercile of the right skew, but not in the high tercile, the formal tests of stochastic dominance resoundly reject the null hypothesis of non-dominance for the 14-day and seven-day options and for all portfolio selection criteria with only somehow weaker results for 28-day options. We conclude that stochastic dominance is prevalent when the right skew is low.

These results motivate our examination of the characteristics of the options that are included in the dominating portfolios. We find that most of the trading occurs in call options, consistent with the above conclusion that the right skew, but not the left one, influences our results.

\section{Characteristics of the Dominating Portfolios}

\subsection{Characteristics of the options in the zero-net-cost portfolios}

In Table 7 we describe the composition of the zero-net-cost portfolios. The total number of contracts in each category is the sum of the absolute values of the number of long and short contracts. We present results for the entire available sample period and before, during, and after the financial crisis. We present the results for the Sharpe ratio portfolio selection criterion, defined in Section 4, since the unreported results for the other criteria are qualitatively similar.

[Table 7 here] 
For the 28-, 14-, and seven-day options, over the whole sample period and in the subperiod before the financial crisis, the total number of call contracts is more than double the number of put contracts. In the subperiod after the financial crisis the total number of call contracts is more than double the number of put contracts for 14- and seven-day options but the total number of call contracts is about the same as the number of put contracts for 28-day options.

For the 28-, 14-, and seven-day options, over the whole sample period and in the subperiods before and after the financial crisis, the call positions are overwhelmingly short positions. Thus the OT investor creates the dominating portfolio by primarily writing calls, consistent with the observation that portfolio managers often write covered calls. The put positions are evenly divided between long and short positions before the crisis and are primarily short positions after the crisis. Thus calls are more overpriced than puts despite the steep implied volatility skew and consistent with the earlier findings in Constantinides, Jackwerth, and Perrakis (2009) and Constantinides, Czerwonko, Jackwerth, and Perrakis (2011).

The 12-month period from 2008.11 to 2009.10 of the financial crisis is different. The total number of put positions is double the number of call positions. Furthermore the put positions are overwhelmingly short positions. Our interpretation is that during the crisis prices overreacted to the prospect of a financial disaster and the slope of the skew steepened to the point that it became attractive to the OT investor to write overpriced puts rather than calls.

For the 14-day and seven-day options we observe a gradual decrease in put trading as the maturity gets shorter. This decrease is especially pronounced during the period of the financial crisis when we observe the majority of trading in put options for 28 days to maturity, about equal trading in calls and puts for 14 days to maturity, and only a small fraction of trading in put options for seven days to maturity. We also observe a gradual increase in short call positions as the maturity gets shorter. OT put usage goes down sharply with maturity, especially during the crisis. Since we keep the lowest support at 0.6 for all maturities, it is obvious that going down that far is going to be much less probable in shorter time, thus resulting in lower-priced protective puts.

In Table 8 we present the percentage of the months out of the total number of sample months in which $0,1,2$, or 3 types of 28-day options are included in the optimal zero-net-cost portfolios. For example, in the first row of the table no OTM short calls are included in $11.7 \%$ of the sample months; and OTM short calls with two different strike-to-price ratio are included in 
$5.5 \%$ of the sample months. ATM calls are included in the category of ITM calls; and ATM puts are included in the category of ITM puts. We present results when the selection criterion is the Sharpe ratio. We obtain similar results when we use the other selection criteria.

[Table 8 here]

Over the whole sample period and in the subperiods before and after the financial crisis most of the calls and puts in the optimal zero-net-cost portfolios are OTM options as opposed to ITM options (with ATM options included in the category of ITM options). This is consistent with the observation that OTM options are more liquid that ITM options and the volume of trading in OTM options is higher than the volume of ITM options.

Over the whole sample period and in the subperiods before and after the financial crisis the OT investor primarily transfers payoffs from the high market return states to the low market return states by writing OTM calls. In most months the OT investor writes only one and at most two types of OTM calls. In the subperiod before the financial crisis second in frequency of options included in the optimal zero-net-cost portfolios are long positions in OTM puts and calls. In the subperiod after the financial crisis second in frequency of options included in the optimal zero-net-cost portfolio are long positions in OTM calls; and long and short positions in OTM puts. Here again most often only one type of option in each category is included in the portfolio. Of interest is also the observation that long and short positions in OTM puts are approximately equal in size, implying that the net OTM put position is hedged at the left tail of the index support, as required for stochastic dominance. The put options appear to be aimed primarily at achieving a desirable payoff pattern at low and intermediate parts of the support.

As we observed earlier the period of the financial crisis is different. The OT investor primarily writes OTM puts. Second in frequency of options included in the optimal zero-net-cost portfolio are short ITM and OTM calls and long OTM puts. The long puts, both OTM and ITM, combine with the OTM puts to establish the net non-negative position at the left tail.

Over the whole sample period and in all the subperiods the option portfolios are parsimonious. For example, over the whole sample period, OTM short calls of only one strike-toprice ratio appear in $82.8 \%$ of the sample months, but only in $5.5 \%$ of the sample months OTM short calls with two or more different strike-to-price ratio appear in the option portfolios. The same observation applies to all the other categories of options, ITM short calls, OTM long calls, and so 
on. The results for 14-day and seven-day options are similar to the results reported in Table 8 for 28-day options and are not shown.

In unreported results we allow the OT portfolio to include a long or short position in the index, over and above the initial position of one index unit and include it as part of the payoff $A\left(S_{t+1}\right)$ at option maturity. A priori we do not expect this variant of the program to result in additional acquisition of the index since it would increase the left tail risk, contrary to the objectives of stochastic dominance; it may, however, potentially increase the attractiveness of writing puts. ${ }^{16}$ This relaxation of our program brings in fact little change in the OT portfolio composition. Depending on the portfolio selection criterion, the OT portfolio does include a short position in the index at one or two dates in our sample, with these dates corresponding to the period of the financial crisis. We also estimate the portfolios after eliminating the $0.25 \%$ transaction cost in the index. The main result is that the OT portfolios now contain positions in short index units that are about $10-13 \%$ on average, which allow some increase in the number of puts; the latter remain, however, much lower than the calls in the OT composition. Otherwise the excess returns of the OT portfolios remain approximately the same even though their standard errors decrease and they become significantly positive everywhere.

\subsection{Option characteristics in relation to the IV smile}

In Table 9 we present the characteristics of calls in relation to the ATM IV, left skew, and right skew in the 1990.01-2013.02 period. We present results for the Sharpe ratio portfolio selection criterion. Left (right) skew is 5\% OTM IV (5\% ITM IV) net of the ATM IV for a given crosssection. The total number of contracts in each category is the sum of the absolute values of the number of long and short contracts. Each tercile for a given smile characteristic corresponds to 92 observations.

[Table 9 here]

\footnotetext{
${ }^{16}$ In principle an increased quantity of the underlying may increase the attractiveness of writing calls; however, with our restriction of at most one call, there is no need to carry more of the underlying to arrive at the stochastically dominating payoff.
} 
In earlier Table 8 we show that most of the calls in the optimal zero-net-cost portfolios are short contracts as opposed to long ones. In Table 9 we establish that this conclusion is robust to the ATM IV and the size of the left and right skew. The number of short calls is higher when the ATM IV is low and/or the right skew is high. Furthermore the number of calls in the OT portfolio, both long and short, increases or stays the same in all cases as the maturity gets shorter.

In Table 10 we present the corresponding characteristics for puts. The number of short and long puts is higher when the ATM IV is high and/or the right skew is low. Here the number of puts in the OT portfolio varies inversely with the number of calls, decreasing or staying the same in all cases for shorter maturities. This indicates that put overpricing is much less pronounced for shorter maturities since the probability that there will be a crash till option expiration is correspondingly lower. It is probable that the parallel increase in the number of calls noted in Table 9 takes place because the constraint in the total number of options in the OT portfolio is now less binding on the calls which remain overpriced.

[Table 10 here]

Since over the whole sample period and in the subperiods before and after the financial crisis the OT investor primarily transfers payoffs from the high market return states to the low market return states by writing OTM calls, we address the question whether all types of options are needed for profitable OT portfolios. First we allow trades in only short calls but not in long calls, long puts, and short puts, without changing the program objectives. Then we allow trades in both short and long calls but not in puts. In unreported results we find that with only short calls the results are weak; the inclusion of long calls improves the results but even so there are fewer feasible portfolios (234, 264, and 260 respectively for 28-, 14- , and seven-day options) than in Table 2. Hence, trading in long calls and in puts significantly enhances the performance of the OT portfolios even though these options are relatively less important than OTM calls in most months.

\subsection{Are the options in the OT portfolios special?}

Our results beg the question as to whether the options in the optimal portfolios are special. Recall that, in the "first pass" columns of Table 1, we show that the average number of separate contracts in the option portfolios is low, exceeding four in only one case. This is surprising given the number 
of available options in each cross-section. For 28-day options this number rises from 16.4 in the beginning of the sample period to more than four times as much in the later periods. In other words the option portfolios contain more than $20 \%$ of the available options in the earlier cross-sections but a much lower proportion in the later ones.

We address whether our search for mispriced options exhausts the options that produce dominating OT portfolios by removing from each cross-section the options that are included in the optimal portfolio - the "first pass" options - and repeating the search with the remaining options in the cross-section. Only the cross-sections with at least three calls and puts are admitted in the sample.

In Table 11 we present results for four different portfolio selection criteria: the Sharpe ratio, gain/loss ratio, Sortino ratio, and the maximization of $\widehat{S} . \quad \mu$ is the mean and $\sigma_{O T-I T}$ is the volatility of the difference of the annualized percentage return between the OT and IT portfolios. In the top panel we present results for portfolios constructed 28 days to the option maturity; out of the 278 dates there are 265 dates with feasible portfolios. In the middle panel we present results for portfolios constructed 14 days to the option maturity; out of the 278 dates there are 265 dates with feasible portfolios. In the bottom panel we present results for portfolios constructed seven days to the option maturity; out of the 278 dates there are 270 dates with feasible portfolios. The volatility of the return of the 28-day, 14-day, and seven-day IT portfolios is $16.48 \%, 17.15 \%$, and $18.12 \%$, respectively. Statistical tests are performed on the basis of the total number of dates. The $p$-values for the difference in means are derived via bootstrap with 10,000 draws. For the DD test $10 \%$ trimming (deleting sequentially lowest outcomes in either return set) in the left tail is uniformly performed while similar trimming in the right tail is as shown. The results of the DD tests without trimming in the right tail are not shown because they are qualitatively the same as the $p$-values for the difference in means.

\section{[Table 11 here]}

The results are weaker than the main results in Table 2, yet they remain strong for 14-day and seven-day options. The statistical tests reject the null of non-dominance in all cases for these two sets of options. However for 28-day options the null of non-dominance is rejected only for $10 \%$ trimming in the right tail with the low overall means indicating little stability in the results. 


\subsection{Does the OT investor achieve higher returns by simply trading outliers from the IV smile?}

A potential criticism of the stochastic dominance of the OT portfolios over the IT portfolios is that the OT investor essentially adopts the common trading strategy of buying options that lie below the IV smile and writing options that lie above it. Recall that a higher mean return of the OT portfolio over the IT portfolio is a necessary but not sufficient condition for stochastic dominance. In any case we examine whether the observed higher mean return of the OT portfolios over the IT portfolios is attained by the OT investor's buying options that lie below the IV skew and writing options that lie above it.

In each cross-section we regress the spread midpoint of the $I V_{i}$ of all options that pass all our filters except for the moneyness filter on each option's moneyness, $K_{i} / S_{t}$, and its squared value: $I V_{i}=a+b\left(K_{i} / S_{t}\right)+c\left(K_{i} / S_{t}\right)^{2}+e_{i}$. We run separate regressions for puts and calls.

In Table 12 we report the means and $t$-stats of the residuals of the options that enter the optimal portfolios in units of the annualized IV in percentage points. For example, for short calls in the first line of the table, the mean residual 0.09 implies that short calls in the optimal portfolio have, on average, annualized IV $0.09 \%$ above the skew. For all three maturities we observe similar average positive residuals; however the corresponding standardized residuals are slightly below zero implying that the main ingredient of the zero net-cost portfolios is on average located almost exactly at the smile. For all three maturities short puts have, on average, positive residuals, while long calls and puts have, on average, negative residuals. All these three option categories independently of maturity have residuals generally higher in magnitude than short calls; however as we argued before these categories of options bear less weight in zero-net-cost portfolios than short calls. The standardized residuals are standardized each month by the standard deviation of the residuals in that month.

[Table 12 here]

For all three maturities the mean values of the residuals are positive for short positions and negative for long ones, consistent with the above conjecture. The standardized residuals are statistically significant for the long calls and long puts. However we argue below that these results are economically insignificant. 
Consider first the short calls in the 28-day option portfolios. These calls have mean residual 0.09 . Assuming that the index price is one, the annualized volatility of the index is $18 \%$, the dividend yield is $2 \%$, and the risk free rate is $2 \%$, the Vega of a 28 -day ATM European call is 0.0011 . That is the call is overpriced by $0.09 \times 0.0011=0.000099 \% 0$. If the OT investor were to write the maximum allowed number of such calls (one call per index unit) the sale of these calls would increase the annualized excess return of the OT portfolio by $12 \times 0.000099=0.12 \%$.

We perform the corresponding calculations for the long calls, short puts, and long puts: if the OT investor were to buy the maximum allowed number of calls (one call per index unit) the purchase of these calls would increase the annualized excess return of the OT portfolio by $0.2345 \%$; if the OT investor were to buy the maximum allowed number of puts the purchase of these puts would increase the annualized excess return of the OT portfolio by $0.4827 \%$; and if the OT investor were to write the maximum allowed number of puts the writing of these puts would increase the annualized excess return of the OT portfolio by $0.2650 \%$. From the first row of Table 6 we know that the OT investor writes, on average, 0.60 calls, buys 0.12 calls, writes 0.17 puts, and buys 0.10 puts. Therefore the contribution to the higher annual mean return of the OT portfolios in buying options that lie below the IV skew and writing options that lie above it is about $0.60 \times 0.1188+0.12 \times 0.2345+0.17 \times 0.2620+0.10 \times 0.4827=0.19 \% . \quad$ This contribution is small compared to the difference between the mean return of the OT and IT portfolios, $\mu$, in Table 2 .

Repeating these calculations for 14-day and seven-day options yields the respective contributions of $0.21 \%$ and $0.29 \%$, which yield even smaller fractions of the overall excess return of the OT portfolios. For seven-day options the contribution is $0.79 \%$, which is large but still a fraction of the overall excess return of the OT portfolios. We conclude that, even though 'expensive' or 'cheap' options contribute to the excess return of the OT portfolios, they are not the main driver of the stochastic dominance results.

Apart from the fact that our portfolios incorporate realistic trading prices, which are not represented by the midpoint prices used in the above exercise, they are chosen strategically in order to shift the probability weight to the "low" states of the index return and attain superior risk adjusted expected returns. A policy of trading outliers of the IV skew, even if it can be achieved at zero cost, is unlikely to achieve ex post OT dominance without such features. 


\section{Is the Excess Return of the Option Portfolio Reward for}

\section{Risk?}

Our stochastic dominance tests are based on the maintained hypothesis that the index return is the only priced factor and the stochastic discount factor is monotone decreasing in the index return. This maintained hypothesis further implies that the documented excess returns of the OT portfolios, adjusted for market risk, are positive. In this section we test whether the excess returns of the OT portfolios are rewards for risks that are not taken into account in our theoretical setup. We consider the three factors in Fama and French (1993), the factors "Jump", "Volatility Jump", "Volatility", and "Liquidity" which have been shown in Constantinides, Jackwerth, and Savov (2013) to explain the cross-section of S\&P 500 option returns, and the Christoffersen, Heston and Jacobs (2013) extension of the Heston and Nandi (2000) stochastic discount factor which is $U$ shaped in index returns.

\subsection{Construction of option portfolio returns over calendar months}

We construct 28-day option portfolio returns with holding period that approximately coincide with calendar months. ${ }^{17}$ At the beginning of a month we construct the OT options portfolio by buying and writing options that were originally issued as 28-day options. One, two, and three weeks later we close out our positions (or, exercise them if they expire and are in the money) and construct a new OT options portfolio by buying and writing options that were originally issued as 28-day options. The one-month excess return of the OT options portfolio, $r_{O T, t}$, is the sum of the cash flows of these trades divided by the index value at the end of the previous month.

The OT portfolios are chosen in the presence of transaction costs as in the previous sections and then the bid or ask price at which an option is written or purchased is replaced by the corresponding bid-ask midpoint, as is commonly done in this literature. Note, however, that unlike

\footnotetext{
${ }^{17}$ For our earlier results we construct the OT option portfolios of 28-day options by buying or writing the options when they are 28 days to maturity which is at the end of the third week of the month and holding them till expiration which is at the end of the third week of the following month. Thus the holding period of 28-day options does not coincide with a calendar month. We also construct the OT option portfolios of 21-, 14-, and seven-day options in a similar fashion. The OT option portfolios of 21- and 14-day options may or may not expire within the same calendar month but the seven-day options expire within the same calendar month. For our earlier results it is immaterial that the holding period does not coincide with a calendar month.
} 
earlier studies we do not assume that the put-call parity holds in order not to interfere with option market data. Since the short option positions now have higher prices and the long positions have lower prices the resulting realized excess OT payoffs are higher by about one-half the bid-ask spread.

\subsection{Factor-adjusted option portfolio returns}

For the first test we adjust the excess returns of the OT options portfolio with the three factors in Fama and French (1993) by running the time-series regression

$$
r_{O T, t}=\alpha+\beta_{M} r_{M, t}+\beta_{S M B} r_{S M B, t}+\beta_{H M L} r_{H M L, t}+\varepsilon_{t}
$$

where $r_{O T, t}, r_{M, t}, r_{S M B, t}$, and $r_{H M L, t}$ are the excess returns of the OT, market, small-minus-big (SMB), and high book-to-market minus low book-to-market (HML) portfolios in month $t$; and $\alpha$ is the risk-adjusted average excess return of the OT portfolio. Table 13 shows that the risk-adjusted average excess return of the OT portfolio is positive and highly significant partly because the factor loadings on the SMB and HML factors are small and marginally significant. We conclude that the three-factor model in Fama and French (1993) does not explain away the average excess return of the OT portfolio.

\section{[Table 13 here]}

For the second set of tests we adjust the excess returns of the OT options portfolio with the market and, each one in turn, the factors "Jump", "Volatility Jump", "Volatility", and "Liquidity" which have been shown in Constantinides, Jackwerth, and Savov (2013) to explain the crosssection of S\&P 500 option returns. In the first stage we estimate the factor loading $\beta_{f}$ from the time-series regression $r_{O T, t}=\alpha+\beta_{M} r_{M, t}+\beta_{f} f_{t}+\varepsilon_{t}$, where $r_{O T, t}$ and $r_{M, t}$ are the excess returns of the OT and market portfolios and $f_{t}$ is the realization of the factor "Jump", "Volatility Jump", "Volatility", or "Liquidity". The risk prices of these factors, $\lambda_{\text {Jump }}, \lambda_{\text {VolJump }}, \lambda_{\text {Vol }}$, and $\lambda_{\text {Liq }}$, are estimated in Constantinides, Jackwerth, and Savov (2013) over the same time period either from the universe of equities or from the universe of index options. In the second stage we estimate the risk-adjusted average excess portfolio return, $\overline{r_{O T, t}-\beta_{M} r_{M, t}-\beta_{f} \lambda_{f}}$. Table 14 shows that the riskadjusted average excess return of the OT portfolios is positive and highly significant in all cases. 
We conclude that the Constantinides, Jackwerth, and Savov (2013) model does not explain away the average excess return of the OT portfolios.

[Table 14 here]

\subsection{Option portfolio returns adjusted for risk and valued with the Christoffersen, Heston, and Jacobs (2013) stochastic discount factor}

Jackwerth (2000) was the first to introduce a non-monotonic stochastic discount factor to explain option prices. Non-monotonicity under the form of a $U$-shaped stochastic discount factor is, in fact, the explanation given for the anomalous in-sample results for individual options in Constantinides, Jackwerth, and Perrakis (2009) by Bakshi, Madan, and Panayotov (2010), Beare (2011), and Beare and Schmidt (2016). A $U$-shaped stochastic discount factor captures an important empirical observation for extreme positive index returns. Such returns occur when the overall volatility is very high in situations after a market crash, as it happened for about a year following the recent financial crisis.

We examine whether the $U$-shaped stochastic discount factor correctly prices the identified OT portfolios. We apply the Christoffersen, Heston, and Jacobs (2013) extension of the Heston and Nandi (2000) stochastic discount factor which is $U$-shaped in index returns and may potentially explain away the average excess return of the OT portfolio. This is the only such model available in the literature containing closed-form expressions for both options and the stochastic discount factor. We present the essential features of this model and defer technical details to Appendix B. The key feature of this model is that only one parameter, $\xi$, is defined by option market data while the remaining parameters are extracted from the underlying market.

We start by estimating the parameters of the $P$ distribution with GARCH on daily returns. Since the $U$-shaped stochastic discount factor depends on the entire volatility path from the beginning of the month till the option expiration, we filter out the realized volatilities from the realized index returns, given that they both depend on the same random factor. We then determine from the closed-form expressions and the observed option prices the extra volatility pricing parameter $\xi$ needed to price the entire universe of options. This parameter is chosen by maximizing the likelihood for our data. The results for the smaller value of this parameter found 
in Christoffersen, Heston, and Jacobs (2013) are qualitatively similar. To compute the realized stochastic discount factor at time $t, S D F_{t}$, we multiply the realized volatility by $\xi$.

Table 15 presents the average risk-adjusted excess return of the OT portfolios, $\overline{S D F_{t} \times r_{O T, t}}$, where $r_{O T, t}$ is the realization of the excess return of the OT portfolios at time $t$. The risk-adjusted excess returns on OT portfolios assume extreme positive values due to the extreme variation in the SDF for the realized paths of the conditional volatility, which variation results in all $t$-statistics in the proximity of one. Moreover the stochastic discount factor is unable to correctly price the index whose risk-adjusted returns assume extreme negative values. We conclude that the Christoffersen, Heston, and Jacobs (2013) stochastic discount factor does not explain away the average excess return of the OT portfolios.

[Table 15 here]

Finally we examine whether the observed OT option prices are consistent with the $U$ shaped stochastic discount factor as extracted from the entire option market data. For this it suffices to compare the predicted model prices with the realized ones in an exercise that parallels the one conducted by Christoffersen, Heston, and Jacobs (2013, Table 2 and pp. 1992-1994) for a policy of shorting straddles which is found to be highly profitable in several studies. ${ }^{18}$ In that exercise the authors consider short straddles worth $10 \%$ of the underlying index and conclude that the straddle returns at model prices are consistent with those observed in the market since they are within the $95 \%$ bootstrapped confidence interval around the market returns.

Table 16 presents the realized average returns at market and model prices for the OT portfolios and straddles as well as the $95 \%$ confidence intervals around the market returns bootstrapped as in Christoffersen, Heston, and Jacobs (2013, Table 2). Since these returns consist of the initial portfolio prices and the realized payoffs which are identical in both cases, the difference between columns 2 and 3 in all panels comes solely from the market and model prices. Recall also that the model prices are the expected payoffs of the options in the portfolios, evaluated by the risk neutral $Q$ distribution of returns and volatilities and the same value of the parameter $\xi$ as in Table 15. To preserve comparability with the Christoffersen, Heston, and Jacobs (2013, Table

\footnotetext{
${ }^{18}$ The literature on the anomalous straddle returns includes Broadie, Chernov, and Johannes (2009), Christoffersen, Heston, and Jacobs (2013), Coval and Shumway (2001), Driessen and Maenhout (2007), and Santa Clara and Saretto (2007).
} 
2) results we normalize the OT portfolios to yield the same initial premium as the $10 \%$ of the underlying index collected via the short straddles at each date, while the portfolio excess returns are derived relative to one unit of index as before.

[Table 16 here]

The highly significant straddle returns in our table can be compared to those of Christoffersen, Heston, and Jacobs (2013, p. 1982, Table 2) only for the 28-day options for which the Christoffersen, Heston, and Jacobs (2013) results are more than twice as high, reflecting the post-crisis years in our data. By contrast their model returns at $1.82 \%$ are of the same order of magnitude as ours in column 3 of panel B. On the other hand it is clear that for the same collected premium the optimal OT portfolios yield higher returns but not necessarily lower p-values than the corresponding straddles. Similarly in panel $\mathrm{C}$ of the table we observe that the difference in means between OT portfolios and straddles is always significant at $10 \%$ or better.

Most important, however, is the fact that the model prices lie far above the $95 \%$ confidence interval around the market price in the second column for both OT portfolios and straddles as well as their differences, in sharp contrast to the consistency between market and model prices observed in the earlier study for the 28-day options. This inconsistency holds for the 28-, 21- and 14-day OT portfolios and straddles, and only for the highly volatile seven-day maturity options do the OT portfolio and straddle confidence intervals encompass the model prices. We conclude that the observed option prices in the OT portfolios are not consistent with the Christoffersen, Heston, and Jacobs (2013) $U$-shaped stochastic discount factor. ${ }^{19}$

\section{Robustness Tests}

\subsection{Mispriced OT portfolios for the CAC and DAX indices}

In Table 17 we show the results for the mispriced 28-, 14-, and seven-day OT portfolios extracted from options on the CAC and DAX indices, together with the contemporaneous sample of January

\footnotetext{
${ }^{19}$ In unreported results we reverse the exercise and show that the value of $\xi$ that prices correctly the OT portfolios generates highly biased model prices for the entire cross section.
} 
2006 to February 2013 S\&P 500 options while for weekly options the sample starts in June 2006. Weekly options, i.e. S\&P 500 and DAX options which are listed about a week before the maturity on Fridays other than the third Friday of a given month, are considered separately. We use the Sharpe ratio criterion and show all the information presented for that criterion in Table 2 , together with the sample sizes in each case and the dates where feasible dominating OT portfolios could be extracted.

[Table 17 here]

The table shows that the results for all indices are qualitatively similar although the feasibility is somewhat reduced for the two European indices from the impressive 272 out of 278 (approximately 98\%) in the entire sample of the S\&P 500 index, which is virtually the same in the shorter sample. Still the feasibility is more than $90 \%$ in all but one of the six cases in which it is $82 \%$. The strong maturity effect on in-sample OT profitability is clear for all three indices, with the seven-day options recording an impressive excess return of over $5 \%$ everywhere, much higher than for the entire S\&P 500 sample in Table 2. The similarity of the results for all three indices extends to the out-of-sample DD tests which are not significant for the 28-day maturity OT portfolios but strongly significant for the other two maturities. Clearly the size of the time series sample accounts for the difference between the first panel of Table 2 and the last panel of Table 16. We conclude that the mispricing effect of OT portfolios dominating the index extends to the two other indices that are examined.

The results for weekly options for S\&P 500 and DAX are similar to each other but distinct from the results for seven-day options. Weekly options exhibit both lower profitability and lower feasibility in relation to their seven-day counterparts, i.e. the profitability decreases from over 5\% to about $2 \%$ per annum while the feasibility decreases from well over $90 \%$ to about $75 \%$ for S\&P 500 and to $50 \%$ for DAX.

\subsection{Alternative volatility projections for the return distribution}

Volatility projections are a key element of our stochastic dominance tests. Our base case method is forward-looking, in the sense that it uses the VIX, which is corrected on the basis of the observed average error for its well-known upward bias. Here we also consider alternative projection 
methods, based on two GARCH models, the Glosten, Jagannathan, and Runkle (GJR, 1993) and the exponential EGARCH model of Nelson (1991), as well as an ad hoc random walk volatility model.

The following expressions indicate the assumed dynamics under the two daily GARCH models with $t$ and $t+1$ indicating two successive days and $h_{t}$ the variance at $t$.

GJR:

$\ln \frac{S_{t+1}}{S_{t}}=\mu+\sqrt{h_{t}} \varepsilon_{t+1}, \quad h_{t}=\omega+\left(\alpha+\gamma I_{t-1}\right) \varepsilon_{t-1}^{2}+\beta h_{t-1}, I_{t-1}=0$ if $\varepsilon_{t-1} \geq 0, I_{t-1}=1$ if $\varepsilon_{t-1}<0$

and

EGARCH:

$\ln \frac{S_{t+1}}{S_{t}}=\mu+\sqrt{h_{t}} \varepsilon_{t+1}, \ln \left(h_{t}\right)=\omega+\alpha\left(\left|\varepsilon_{t-1}\right|-E\left|\varepsilon_{t-1}\right|\right)+\gamma \varepsilon_{t-1}+\beta \ln \left(h_{t-1}\right)$

where $\varepsilon_{t+1}$ is standard normal conditional on the information set at time $t$. For the GJR model the following recursive expression allows the estimation of total return volatility over the life of the option: $h_{t+1}=\omega+\left(\alpha+\frac{\gamma}{2}+\beta\right) h_{t}$.

For each GARCH application we estimate the model coefficients over a rolling window of 3,800 daily observations, corresponding to approximately 15 years of data. For the GJR model we project the volatility by summing the forecasted conditional variances given the estimated coefficients and the above recursive expression. For the EGARCH model we sum the forecasted conditional variances evaluated by simulating 100,000 return paths. Random walk projected volatility is simply the sample volatility realized just before each trading date over the same number of days as the option maturity. Table 18 presents the results for the Sharpe ratio criterion for 28-, 14- , and seven- day maturities, which should to be compared to our base case adjusted VIX method in Table 2.

[Table 18 here]

We find evidence of mispricing in all panels which is confirmed ex post at all maturities for either the GJR or EGARCH forecast methods, with somewhat lower profitability compared to 
our base case except for the seven-day options under EGARCH forecasts. The results are generally weaker for the random walk case, insofar as they exhibit no evidence of stochastic dominance for 28-day options either in-sample or ex post. All three models, especially the two GARCH ones, also yield a significantly lower number of feasible dates than our base case.

In unreported results we further analyze the relationship between the quality of the forecasts and the stochastic dominance results by estimating basic statistics such as the bias and

the variability of the forecast error $\varepsilon_{t, P} \equiv \sqrt{h_{t, P R E D}}-\sqrt{h_{t, O B S}}$, predicted minus observed volatility. We observe that VIX-adjusted is at par with both GARCH models with respect to the forecast quality, but both GARCH models produce positive biases of similar magnitude which are similar to the negative bias for the adjusted VIX. The random walk produces a small bias but its forecast error dispersion measures are clearly inferior to the other three methods. These results explain the lower number of feasible dates for the two GARCH methods since the net short position of our OT portfolios tends to produce lower in-sample expected payoffs when the predicted volatility is high. We conclude that the mispricing of the OT portfolios exists in all volatility prediction models and that the adjusted VIX method is the most efficient of all candidate methods in identifying them.

\subsection{Alternative assumptions on mean premium on the index return}

In Table 19 we present the counterpart of Table 2 for the Sharpe ratio selection criterion but replacing the $4 \%$ assumed premium on the index return by $2 \%$ and $6 \%$. The results are virtually identical to those in Table 2, thereby demonstrating that the results are robust to the assumed premium on the index return.

[Table 19 here]

\subsection{Trading results with restricted option choices}

We show that the OT portfolios uncover violations that go beyond the violations of the Constantinides-Perrakis (2002) call upper bounds by eliminating these violating call options from the choice set. This involves eliminating them from 212, 183, and 199 cross-sections, respectively, for the 28-, 14-, and seven-day maturities. The results are presented in the first panel of Table 20. The OT portfolios stochastically dominate the IT portfolios for all maturity options but we reject 
the hypothesis that the expected return of the IT portfolios is lower than the expected return of the OT portfolios only for the seven-day options. In unreported results we choose the OT portfolios after replacing the violating call options with their upper bounds and find that the expected return of the OT portfolios is significantly higher than the IT return for both the 14- and seven-day options.

\section{[Table 20 here]}

We then consider some popular and allegedly profitable strategies: covered calls, put vertical spreads, and butterfly spreads. We restrict the choice set for the OT portfolios to calls only. The results are shown in the second panel of Table 20. The OT portfolios stochastically dominate the IT portfolios only for 14-day and seven-day options but we cannot reject the hypothesis that the expected return of the IT portfolios is lower than the expected return of the OT portfolios for any maturity options. Finally we restrict the choice set for the OT portfolios to puts only. The results are shown in the third panel of Table 20. The OT portfolios do not stochastically dominate the IT portfolios for any maturity options and we cannot reject the hypothesis that the expected return of the IT portfolios is lower than the expected return of the OT portfolios for any maturity options. In unreported results we restrict the OT choice set to OTM options for both calls and puts. The excess returns decrease by a factor of two for all three maturities and are significant only for the 7-day options.

We conclude that the OT portfolios are profitable because they contain both OTM and ITM calls and puts and both long and short positions. The portfolios cannot be explained by call or put butterflies or vertical spreads and are not an extension of the profitable covered calls identified in Constantinides, Czerwonko, Jackwerth and Perrakis (2011). Further, the observed ITM option prices that are ignored in most frictionless studies are significant contributors to the portfolios' profitability.

\subsection{Stochastic dominance in a frictionless world}

Earlier studies that ignore transaction costs find that it is puts rather than calls that are typically overpriced. In contrast we find that the options portfolios contain far more short calls than long 
calls, short puts, and long puts suggesting that it is calls rather than puts that are overpriced, except during the financial crisis period 2008.11-2009.10 (Table 7).

We explain this difference by applying our portfolio selection algorithm to the frictionless universe of options as defined in most studies. First we calculate the average of the bid and ask prices $\left(P_{a v}\right)$ of OTM calls and OTM puts. We then calculate the corresponding prices $\left(P_{a v}\right)$ of ITM calls and ITM puts from the average prices of the corresponding of OTM calls and OTM puts through the put-call parity. Observe that the ITM options that appear in more than $30 \%$ of the cross-sections play no role in this frictionless data. Finally we obtain the set of adjusted prices $\left(P_{a d j}\right)$ by minimizing the sum of squared deviations $\left(P_{a d j}-P_{a v}\right)^{2}$ subject to the condition that there are no convexity violations. The resulting adjustments never exceed a few cents.

The results of our algorithm for the Sharpe ratio criterion are shown in in the first panel of Table 21 for all three maturities. The average OT excess payoffs have much lower means than the equivalent Table 2 entries but also very low volatilities and are strongly significant. The major difference with the results under frictions lies in the composition of the OT portfolios shown in the bottom panel. Compared to our base case in Table 7 we observe that the shifting of payoff to the low end of the support of the index by shorting calls which take $65 \%$ or more of the portfolio in all three maturities, now takes only about $10 \%$ while the long calls significantly increase. The payoff shifting now takes place by the adoption of relatively large positions in short index and a large increase in short puts. Put options thus appear overvalued in frictionless data even though trading in them to eliminate the over valuation is not feasible under realistic conditions that account for the bid and ask prices. This resolves the differences with earlier studies that ignore transaction costs.

[Table 21 here]

\section{Concluding Remarks}

We show that at least some S\&P 500 options are significantly mispriced relative to the index. A utility-maximizing investor trading at 28, or 14, or seven-day intervals in the S\&P 500 index and 
a risk free bond, subject to proportional transaction costs, stochastically dominates her portfolio by overlaying a zero-net-cost portfolio of European S\&P 500 options bought at their ask price and written at their bid price in almost every month from 1990 to 2013. Dominance is prevalent when the ATM IV is high and/or the right skew is low. The portfolios include about twice the number of calls than puts and the call positions are overwhelmingly short positions, consistent with the practice of writing covered calls. This contradicts the common belief that puts but not calls are overvalued, which we attribute to the neglect of trading costs and the methodology of creating the frictionless option universe. Similar results obtain with options on the CAC and DAX indices. The mispricing is explained by neither priced factors nor the non-monotonicity of the stochastic discount factor.

There are a number of possible reasons as to why this mispricing persists. Index funds and ETFs minimize tracking error and the inclusion of options in their portfolios would likely increase tracking error. Passive mutual funds may find it difficult to communicate to their investors the benefits of stochastic dominance which require a significant length of time to show up and may not be suitable for investors seeking quick returns. Other active mutual funds and hedge funds may not hold the market portfolio because they have different priorities such as picking winners or enhancing their portfolio returns by skewing their holdings towards small-capitalization, value, or high profitability stocks. Finally option traders' and intermediaries' credit constraints and funding liquidity may distort the prices of index options. In any case it remains to be seen whether this paper's demonstration of the large OT excess returns will alter investors' behavior and eliminate the documented anomaly. 


\section{Appendix A: The numerical algorithm}

We search for optimal OT portfolios by solving an LP under a set of constraints. Let $w_{i} \geq 0, i=1, \ldots, 2 n$ denote the number of options $C_{i}$ (both calls and puts) entering into the OT portfolio from the $n$ available options in a given cross section, ordered in ascending strike price. We treat long and short option positions as separate options, thus allowing us to restrict linearly the total option position. Let also $\Pi$ denote the initial value of the OT portfolio. We have:

$$
0 \leq \sum_{1}^{2 n} w_{i} \leq 1, \quad \Pi=\sum_{1}^{2 n} w_{i} C_{i}
$$

Then, if $g_{i}\left(S_{t+1}\right)$ denotes the payoff of the $i^{\text {th }}$ option, the total payoff at option expiration equals

$\Pi R+\sum_{1}^{2 n} w_{i} g_{i}\left(S_{t+1}\right)$. We then have by definition

$$
A\left(S_{t+1}\right)=\left(\begin{array}{ll}
\frac{\Pi R+\sum_{1}^{2 n} w_{i} g_{i}\left(S_{t+1}\right)}{1+k}, & S_{t+1} \leq \hat{S}, \\
\frac{\Pi R+\sum_{1}^{2 n} w_{i} g_{i}\left(S_{t+1}\right)}{1-k}, & S_{t+1}>\hat{S}
\end{array}\right)
$$

Observe that $A\left(S_{t+1}\right)$ is piecewise linear, with a constant slope $\frac{\partial A}{\partial S_{t+1}}$ within any interval $\left[K_{j}+, K_{j+1}\right)$ of two successive strike prices $K_{j}, j=1, \ldots, n$ of the available strike prices in the option cross section. We add the fundamental stochastic dominance constraints

$$
A\left(S_{t+1}\right)>0 \text { for } 0.6 S_{t} \leq S_{t+1} \leq \hat{S} ; A\left(S_{t+1}\right) \leq 0 \text { for } S_{t+1}>\hat{S} ; E_{t}\left[A\left(S_{t+1}\right)\right] \geq 0 .
$$

These constraints need only be verified at the strike prices to the left of $\widehat{S}$, while at the right we simplify the search by adding the constraint that the payoff be non-increasing. Last, we find the OT portfolio by solving the following LP.

$$
\operatorname{Max}_{w_{i}} E_{t}\left[A\left(S_{t+1}\right)\right] \text { given } \hat{S} \text {, }
$$


subject to (A.1)-(A.3). If this program is feasible then the set of optimal weights and corresponding options $\left\{w_{i}^{*} \neq 0, C_{i}^{*}\right\}$ belongs to the ex ante stochastically dominant set $\Omega(\hat{S})$ of OT portfolios. ${ }^{20}$

In our search we vary $\hat{S}$ till the LP becomes infeasible for some maximum value of $S_{t+1}=\hat{S}$, arbitrarily restricted to $1.15 S_{t}$. We restrict our search to the segment $\left[S_{t}, 1.15 S_{t}\right]$. Once this maximum feasible value for $\widehat{S}$ is found we partition the segment $\left[S_{t}, \hat{S}\right]$ and maximize the excess return to OT for each value of this partition to find the complete set $\Omega(\hat{S})$. Finally the optimal portfolio is defined as the one for which a given selection criterion reaches its supremum.

${ }^{20}$ Since the LP has a trivial solution of all zero weights we constrain the sum of weights in the first constraint of (A.1) to be above some low threshold, $10^{-4}$ in our applications. 


\section{Appendix B: The Christoffersen, Heston, and Jacobs (CHJ, 2013) extension of the \\ Heston and Nandi (2000) GARCH process}

We modify our notation by denoting the option maturity time by $T$ instead of $t+1$ and estimate a GARCH model, the physical or $P$-distribution of daily index return data over a time period that covers the entire data set and includes all option maturities. The risk-neutral or $Q$-distribution is found from the stochastic discount factor that transforms the parameters of the physical distribution and includes parameters reflecting investor preferences with respect to return and volatility. The asset dynamics are given by

$$
\begin{aligned}
& \ln \left(S_{\tau}\right)=\ln \left(S_{\tau-1}\right)+r+\left(\mu-\frac{1}{2} h_{\tau}\right)+\sqrt{h_{\tau}} \varepsilon_{\tau} \\
& h_{\tau}=\omega+\beta h_{\tau-1}+\alpha\left(\varepsilon_{\tau-1}-\gamma \sqrt{h_{\tau-1}}\right)^{2}, \quad \tau=1, \ldots, T,
\end{aligned}
$$

where $T$ denotes the upper range of the return data.

Since the conditional density of the daily GARCH returns is normal, the log-likelihood function is ${ }^{21}$

$$
\log L^{P}=-\frac{1}{2} \sum_{t+1}^{\mathrm{T}}\left(\ln (h(\tau))+\frac{\left[\ln S_{\tau}-\ln S_{\tau-1}-r-\left(\mu-\frac{1}{2} h(\tau)\right)\right]^{2}}{h(\tau)}\right) .
$$

The corresponding risk neutral process has the same form as (B.1) but has instantaneous expected return equal to $r$ and a volatility parameter set $\Omega_{Q}=\left\{\omega^{*}, \beta^{*}, \alpha^{*}, \gamma^{*}\right\}$, with parameters transformed via the stochastic discount factor, which has the form ${ }^{22}$

$$
\frac{M_{T}}{M_{t}}=\left(\frac{S_{T}}{S_{t}}\right)^{\varphi} \exp \left(\delta T+\eta \sum_{t+1}^{T} h_{\tau}+\xi\left(h_{T+1}-h_{t+1}\right)\right) .
$$

The stochastic discount factor parameters $(\delta, \eta, \varphi, \xi)$ are linked to the $P$-distribution set $\Omega_{P}$ and to each other by the following relations:

\footnotetext{
${ }^{21}$ See CHJ (2013, p. 1986).

${ }^{22}$ For a single GARCH period the logarithm of the stochastic discount factor can be expressed as a quadratic function of the random stock return only; see CHJ (2013, Corollary 2, p. 1970). Unfortunately no such closed form expression exists for maturities greater than one day.
} 


$$
\begin{aligned}
& \delta=-(\varphi+1) r-\xi \omega+\frac{1}{2} \ln (1-2 \xi \alpha) ; \varphi=-\left(\mu-\frac{1}{2}+\gamma\right)(1-2 \xi \alpha)+\gamma-\frac{1}{2} \\
& \eta=-\left(\mu-\frac{1}{2}\right) \varphi-\xi \alpha \gamma^{2}+(1-\beta) \xi-\frac{(\varphi-2 \xi \alpha \gamma)^{2}}{2(1-2 \xi \alpha)} .
\end{aligned}
$$

Given the parameter values $\Omega_{P}$, the stochastic discount factor has exactly one extra parameter, $\xi$, since the other three are given by (B.4) once $\xi$ is given. This parameter accounts for the U-shaped stochastic discount factor if $\xi>0$, a requirement for the stochastic discount factor to potentially account for our OT results. ${ }^{23}$ The set $\Omega_{Q}$ is given by the following system:

$$
\begin{aligned}
& h_{t}^{*}=\frac{h_{t}}{1-2 \xi \alpha} ; \quad \omega^{*}=\frac{\omega}{1-2 \xi \alpha} ; \quad \alpha^{*}=\frac{\alpha}{(1-2 \xi \alpha)^{2}} \\
& \gamma^{*}=\gamma-\varphi ; \varphi=-\left(\mu-\frac{1}{2}+\gamma\right)(1-2 \xi \alpha)+\gamma-\frac{1}{2}
\end{aligned}
$$

This system yields a unique set $\Omega_{Q}$ consistent with the $P$-distribution set $\Omega_{P}$ and the parameter $\xi$. In turn, given this $\Omega_{Q}$ the OT portfolio model value can be easily found from the option pricing expressions in CHJ (2013, Appendix D) for each one of the four maturities $\left[\tau_{i}, T\right]$, $i=1,2,3,4$ of 28-, 21-, 14- and seven-day options, respectively. We estimate $\xi$ by maximizing the log-likelihood for all options defined as ${ }^{24}$

$$
\log L^{Q}=-\frac{1}{2} \sum_{i=1}^{N}\left[\log \left(s_{e}^{2}\right)+\frac{e_{i}^{2}}{s_{e}^{2}}\right],
$$

where $e_{i}=\left(I V^{M o d}-I V^{M k t}\right) / I V^{M k t}$ and in place of $s_{e}^{2}$ its sample analog is used, $\hat{s}_{e}^{2}=\frac{1}{N} \sum_{i=1}^{N} e_{i}^{2}$.

The parameter set $\Omega_{P}=\{\mu, \omega, \beta, \alpha, \gamma\}$ of the $P$ distribution contains the risk premium parameter $\mu$ and four volatility parameters and is common to the four maturities $\left[t, T_{i}\right], T_{i}-t=28,21,14$, and 7 for $i=1,2,3,4$, respectively. As in CHJ, it is estimated by filtering daily index returns for a time period bracketing the option data set on both sides. We use return data over the 1984 to 2014 period which contains the option data and apply the sequential

\footnotetext{
${ }^{23}$ See Corollary 3 of Christoffersen, Heston and Jacobs (2013, p. 1970).

${ }^{24}$ Expression (B.6) is virtually identical to expression (24) of CHJ (2013, p. 1986), with the difference that the numerator of the error $e_{i}$ is the difference in actual prices rather than their IV's.
} 
likelihood estimation of Broadie, Chernov, and Johannes (2007), starting from the returns and then proceeding to the option market for any additional parameters. Maximizing the log-likelihood function $\log L^{P}$ given in relation (B.2) we find the $P$-distribution parameter set $\Omega_{P}: \omega=0, \alpha=$ $4.1931 \times 10^{-6}, \beta=0.8467, \gamma=165.17, \mu=2.8161$, and $\log L^{P}=32584.9 .^{25}$

We then estimate $\xi$ and corresponding $Q$-distribution as in $\mathrm{CHJ}$ (2013) or, indeed, as in most, if not all asset pricing models, by using the entire cross-section of available option prices for the four maturities under consideration. ${ }^{26}$ Specifically, put-call parity is imposed for every option in the cross-section, implying that it no longer matters whether puts or calls are used for the estimation, with OTM calls and puts in each cross-section. The likelihood function $\log L^{Q}$ given by (B.6) is then evaluated as a function of $\xi$ and its maximum, $\log L^{Q}=84,704$, is found at $\xi=\xi^{*}=58,933 .{ }^{27}$ This value is significantly higher than the value $\xi=32,839$ implied by the results of Table 5 in CHJ (2013, p. 1992), reflecting the different maturities and the different span of the data in our sample. ${ }^{28}$ Our corresponding $Q$-distribution parameters are $\left(1-2 \alpha \xi^{*}\right)^{-1}=1.9771$, $\omega=0, \alpha=1.6391 \times 10^{-5}, \beta=0.8467$, and $\gamma=85.21$.

The stochastic discount factor is equal to the stochastic discount factor $M_{T} / M_{t}$, with the parameters given by (B.4), the above estimates of the parameter set $\Omega_{P}$, the value $\xi=\xi^{*}$ as above, and the implied realized volatility path $\left(h_{t+1}, \ldots, h_{T+1}\right)$ extracted from the observed daily index returns (B.1) and the corresponding observed errors $\varepsilon_{\tau}$. If $N_{T_{i}}$ denotes the number of feasible crosssections for the corresponding maturity $T_{i}=28,21,14$, and seven days, the average risk-adjusted excess return $\overline{S D F_{t} \times r_{O T, t}}$ of the OT portfolio in Table 15 is given by

$$
\overline{S D F_{t} \times r_{O T, t}}=\frac{1}{N_{T_{i}}} \sum_{t=1}^{t=N_{T_{T}}} \frac{M_{T}}{M_{t}}\left(h_{t+1}, \ldots, h_{T+1}\right) r_{O T, t} .
$$

\footnotetext{
${ }^{25}$ These correspond to a higher return premium and volatility than the corresponding results in CHJ (2013, Table 5), most probably due to our much longer return data set.

${ }^{26}$ Note that there are significantly fewer maturities in these estimations that were used by CHJ (2013, p. 1975), since the latter included all available maturities between two weeks and one year.

${ }^{27}$ Unreported results in our online appendix show that $\log L^{Q}$ is a parabolic function of $\xi$, first increasing and then decreasing after reaching $\xi^{*}$.

${ }^{28}$ CHJ (2013, p. 1975) included all available maturities between two weeks and one year.
} 
As for the returns in Table 16 at model prices for both OT portfolios and straddles, the initial values of the portfolios are estimated as in CHJ (2013, Appendix D), with the above $Q$ distribution parameter set. 


\section{References}

Ait-Sahalia, Y. and A. Lo, 2000, "Nonparametric Risk Management and Implied Risk Aversion," Journal of Econometrics 94, 9-51.

Bakshi, G. S., D. Madan, and G. Panayotov, 2010, "Returns of Claims on the Upside and the Viability of U-shaped Pricing Kernels,” Journal of Financial Economics 97, 130-154.

Barone-Adesi G., R. F. Engle, and L. Mancini, 2008, “A GARCH Option Pricing Model with Filtered Historical Simulation," Review of Financial Studies 21, 1223-1258.

Barone-Adesi G., H. Dall'O H, and V. Vovchak, 2012, “Is the Price Kernel Monotone?," ACRN Journal of Finance and Risk Perspectives 1, 43-68.

Bates, D. S., 2003, Empirical Option Pricing: A Retrospection. Journal of Econometrics 116: 387-404.

Beare, B. K., 2011, "Measure Preserving Derivatives and the Pricing Kernel Puzzle,” Journal of Mathematical Economics 47, 689-697.

Beare, B. K. and L. D. W. Schmidt, 2016, “An Empirical Test of Pricing Kernel Monotonicity," Journal of Applied Econometrics 31, 338-356.

Bliss, R. and N. Panigirtzoglou, 2004, “Option-Implied Risk Aversion Estimates,” Journal of Finance 59, 407-446.

Bondarenko, O., 2014, "Why are Put Options so Expensive?” Quarterly Journal of Finance 4, 145-195.

Broadie, M., M. Chernov, and M. Johannes, 2007, "Model Specification and Risk Premiums: Evidence from Futures Options," Journal of Finance 62, 1453-1490.

Broadie, M., M. Chernov, and M. Johannes, 2009, "Understanding Index Option Returns,” Review of Financial Studies 22, 493-529.

Chabi-Yo, F., R. Garcia, and E. Renault, 2008, "State Dependence Can Explain the Risk Aversion Puzzle," Review of Financial Studies 21, 973-1011.

Chen, H., S. Joslin, and S. Ni, 2016, "Demand for Crash Insurance, Intermediary Constraints, and Risk Premia in Financial Markets," Working paper, MIT and NBER. 
Christoffersen, P., S. L. Heston, and K. Jacobs, 2012, "Capturing Option Anomalies with a Variance-Dependent Pricing Kernel," Review of Financial Studies 26, 1963-2006.

Constantinides, G. M., 1979, "Multiperiod Consumption and Investment Behavior with Convex Transactions Costs," Management Science 25, 1127-1137.

Constantinides, G. M., 1986, "Capital Market Equilibrium with Transaction Costs," Journal of Political Economy 94, 842-862.

Constantinides, G. M., M. Czerwonko, J. C. Jackwerth, and S. Perrakis, 2011, "Are Options on Index Futures Profitable for Risk Averse Investors? Empirical Evidence," Journal of Finance 66, 1407-1437.

Constantinides, G. M., J. C. Jackwerth, and S. Perrakis, 2009, "Mispricing of S\&P 500 Index Options," Review of Financial Studies 22, 1247-1277.

Constantinides, G. M., J. C. Jackwerth, and A. A. Savov, 2013, "The Puzzle of Index Option Returns," Review of Asset Pricing Studies 3, 229-257.

Constantinides, G. M. and L. Lian, 2016, "The Supply and Demand of S\&P 500 Options," Working paper, University of Chicago.

Constantinides, G. M. and S. Perrakis, 2002, "Stochastic Dominance Bounds on Derivative Prices in a Multiperiod Economy with Proportional Transaction Costs," Journal of Economic Dynamics and Control 26, 1323-1352.

Constantinides, G. M. and S. Perrakis, 2007, "Stochastic Dominance Bounds on American Option Prices in Markets with Frictions," Review of Finance 11, 71-115.

Coval, J. D. and T. Shumway, 2001, "Expected Option Returns," Journal of Finance 56, 9831009.

Czerwonko, M. and S. Perrakis, 2016, "Portfolio Selection with Transaction Costs and JumpDiffusion Asset Dynamics I: A Numerical Solution," Quarterly Journal of Finance, forthcoming.

Davidson, R., 2009, “Testing for Restricted Stochastic Dominance: Some Further Results,” Review of Economic Analysis 1, 34-59. 
Davidson, R. and J.-Y. Duclos, 2013, “Testing for Restricted Stochastic Dominance,” Econometric Reviews 32, 84-125.

Driessen, J. and P. J. Maenhout, 2007, “An Empirical Portfolio Perspective on Option Pricing Anomalies," Review of Finance 11, 561-603.

Eraker, B., M. Johannes, and N. Polson, 2003, "The Impact of Jumps in Volatility and Returns," Journal of Finance 58, 1269-1300.

Fama, E. F. and K. R. French, 1993, "Common Risk Factors in the Returns of Stocks and Bonds," Journal of Financial Economics 33, 3-56.

Gârleanu, N., L. H. Pedersen, and A. M. Poteshman, 2009, "Demand-Based Option Pricing," Review of Financial Studies 22: 4259-4299.

Glosten, L. R., R. Jagannathan, and D. E. Runkle, 1993, "On the Relation between the Expected Value and the Volatility of the Nominal Excess Return on Stocks," Journal of Finance 48, 1779-1801.

Ioffe, I. D. and E. Z. Prisman, 2013, “Arbitrage Violations and Implied Valuations: The Option Market," European Journal of Finance 19, 298-327.

Jackwerth, J. C., 2000, "Recovering Risk Aversion from Option Prices and Realized Returns," Review of Financial Studies 13, 433-451.

Levy, H., 1985, "Upper and Lower Bounds of Put and Call Option Value: Stochastic Dominance Approach,” Journal of Finance 40, 1197-1217.

Nelson, D. B, 1991, "Conditional Heteroskedasticity in Asset Returns: A New Approach," Econometrica 59, 347- 70.

Newey, W. K. and K. D. West, 1987, “A Simple, Positive Semi-definite, Heteroskedasticity and Autocorrelation Consistent Covariance Matrix," Econometrica 55, 702-708.

Oancea, I. M. and S. Perrakis, 2014, "From Stochastic Dominance to Black-Scholes: an Alternative Option Pricing Paradigm," Risk and Decision Analysis 5, 99-112.

Perrakis, S. and J. Lefoll, 2000, "Option Pricing and Replication with Transaction Costs and Dividends," Journal of Economic Dynamics and Control 24, 1527-1561. 
Perrakis, S. and P. J. Ryan, 1984, “Option Bounds in Discrete Time,” Journal of Finance 39, 519525.

Ritchken, P. H., 1985, “On Option Pricing Bounds,” Journal of Finance 40, 1219-1233.

Rosenberg, J. V. and R. F. Engle, 2002, "Empirical Pricing Kernels," Journal of Financial Economics 64, 341-372.

Rubinstein, M., 1985, "Nonparametric Tests of Alternative Option Pricing Models Using All Reported Trades and Quotes on the 30 Most Active CBOE Option Classes from August 23, 1976 Through August31, 1978," Journal of Finance 40, 455-480.

Rubinstein, M., 1998, “Edgeworth Binomial Trees,” The Journal of Derivatives 5, 20-27.

Soner, H. M., S. E. Shreve, and J. Cvitanic, 1995, “There is No Nontrivial Hedging Portfolio for Option Pricing with Transaction Costs," The Annals of Applied Probability 5, 327-355.

Santa-Clara, P. and A. Saretto, 2009, “Option Strategies: Good Deals and Margin Calls,” Journal of Financial Markets 12, 391-417.

Ziegler, A., 2007, “Why Does Implied Risk Aversion Smile?” Review of Financial Studies 20, 859-904. 


\section{Table 1: Average Number of Filtered Option Contracts}

The table reports averages of the number of calls and puts in cross-sections and averages of the number of options entering zero net-cost portfolios. First-pass options are options selected when all filtered options are available; secondpass options are those selected when the first-pass options are discarded from the opportunity set.

\begin{tabular}{|c|c|c|c|c|c|c|c|}
\hline Period & Months & $\begin{array}{c}\text { Average \# } \\
\text { of Calls }\end{array}$ & $\begin{array}{c}\text { Average \# } \\
\text { of Calls in } \\
1^{\text {st_Pass }} \\
\text { Portfolios }\end{array}$ & $\begin{array}{c}\text { Average \# } \\
\text { of Calls in } \\
2^{\text {nd }} \text {-Pass } \\
\text { Portfolios }\end{array}$ & $\begin{array}{c}\text { Average \# } \\
\text { of Puts }\end{array}$ & $\begin{array}{c}\text { Average \# } \\
\text { of Puts in } \\
1^{\text {st }} \text {-Pass } \\
\text { Portfolios }\end{array}$ & $\begin{array}{c}\text { Average \# } \\
\text { of Puts in } \\
2^{\text {nd }} \text {-Pass } \\
\text { Portfolios }\end{array}$ \\
\hline \multicolumn{8}{|c|}{ 28-Day Options } \\
\hline $1990.01-2000.12$ & 132 & 7.1 & 2.1 & 1.7 & 9.3 & 1.5 & 1.7 \\
\hline 2001.01-2004.06 & 42 & 12.7 & 2.6 & 2.1 & 18.8 & 1.0 & 0.8 \\
\hline 2004.07-2013.02 & 102 & 21.8 & 2.0 & 2.0 & 44.6 & 2.1 & 1.8 \\
\hline 1990.01-2013.02 & 278 & 17.7 & 2.0 & 2.0 & 34.1 & 1.8 & 1.6 \\
\hline \multicolumn{8}{|c|}{ 14-Day Options } \\
\hline 1990.01-2000.12 & 132 & 6.2 & 2.0 & 1.6 & 8.2 & 1.5 & 1.7 \\
\hline 2001.01-2004.06 & 42 & 10.9 & 2.2 & 2.1 & 16.9 & 1.1 & 1.6 \\
\hline $2004.07-2013.02$ & 102 & 21.0 & 2.2 & 2.0 & 37.2 & 1.6 & 1.7 \\
\hline 1990.01-2013.02 & 278 & 16.9 & 2.1 & 1.9 & 29.0 & 1.6 & 1.7 \\
\hline \multicolumn{8}{|c|}{ 7-Day Options } \\
\hline $1990.01-2000.12$ & 132 & 5.5 & 1.8 & 1.7 & 7.2 & 1.1 & 1.9 \\
\hline $2001.01-2004.06$ & 42 & 9.6 & 1.9 & 1.7 & 14.4 & 0.8 & 1.6 \\
\hline $2004.07-2013.02$ & 102 & 20.0 & 2.3 & 2.1 & 32.7 & 1.1 & 1.4 \\
\hline 1990.01-2013.02 & 132278 & 15.8 & 2.1 & 2.0 & 25.2 & 1.1 & 1.5 \\
\hline
\end{tabular}




\section{Table 2: Portfolio Returns and Stochastic Dominance Tests, 1990.01-2013.02}

The table presents results for four different portfolio selection criteria: the Sharpe ratio, gain/loss ratio, Sortino ratio, and the maximization of $\hat{S} . \mu$ is the mean and $\sigma_{O T-I T}$ is the volatility of the difference of the annualized percentage return between the OT and IT portfolios. In the top panel we present results for portfolios constructed 28 days to the option maturity; out of the 278 dates there are 272 dates with feasible portfolios. In the middle panel we present results for portfolios constructed 14 days to the option maturity; out of the 278 dates there are 270 dates with feasible portfolios. In the bottom panel we present results for portfolios constructed seven days to the option maturity; out of the 278 dates there are 270 dates with feasible portfolios. The volatility of the return of the 28-day, 14-day and sevenday IT portfolios is $16.48 \%, 17.15 \%$, and $18.12 \%$, respectively. Statistical test are performed on the basis of the total number of dates. The $p$-values for the difference in means are derived under via bootstrap with 10,000 draws. For the DD test, 10\% trimming (deleting sequentially lowest outcomes in either return set) in the left tail is uniformly performed while similar trimming in the right tail is as shown. The results of the DD tests without trimming in the right tail are not shown because they are qualitatively the same as the $p$-values for the difference in means.

\begin{tabular}{|c|c|c|c|c|c|c|}
\hline \multirow{2}{*}{$\begin{array}{l}\text { Portfolio } \\
\text { selection } \\
\text { criterion }\end{array}$} & \multirow{2}{*}{$\mu$} & \multirow{2}{*}{$\begin{array}{c}p \text {-value for } \\
\quad \mu \leq 0\end{array}$} & \multirow{2}{*}{$\sigma_{\text {OT }}$} & \multirow{2}{*}{$\sigma_{O T-I T}$} & \multicolumn{2}{|c|}{ DD test $p$-value } \\
\hline & & & & & $5 \%$ trim & $10 \%$ trim \\
\hline \multicolumn{7}{|c|}{ 28-Day Options } \\
\hline Sharpe ratio & 0.50 & 0.112 & 15.89 & 1.97 & 0.039 & 0 \\
\hline Gain/loss ratio & 0.92 & 0.029 & 15.81 & 2.19 & 0.008 & 0 \\
\hline Sortino ratio & 0.45 & 0.128 & 15.90 & 1.97 & 0.045 & 0 \\
\hline $\max \hat{S}$ & 0.66 & 0.057 & 15.92 & 1.89 & 0.008 & 0 \\
\hline \multicolumn{7}{|c|}{ 14-Day Options } \\
\hline Sharpe ratio & 2.07 & 0.062 & 15.68 & 3.99 & 0 & 0 \\
\hline Gain/loss ratio & 2.55 & 0.026 & 15.64 & 3.79 & 0 & 0 \\
\hline Sortino ratio & 1.82 & 0.041 & 15.71 & 3.88 & 0 & 0 \\
\hline $\max \hat{S}$ & 2.15 & 0.051 & 15.76 & 3.73 & 0 & 0 \\
\hline \multicolumn{7}{|c|}{ 7-Day Options } \\
\hline Sharpe ratio & 1.90 & 0.062 & 17.43 & 2.79 & 0 & 0 \\
\hline Gain/loss ratio & 2.72 & 0.008 & 17.36 & 2.49 & 0 & 0 \\
\hline Sortino ratio & 2.24 & 0.038 & 17.45 & 2.82 & 0 & 0 \\
\hline $\max \hat{S}$ & 2.22 & 0.007 & 17.61 & 2.06 & 0 & 0 \\
\hline
\end{tabular}




\section{Table 3: Relation between Stochastic Dominance and the Violation Size, $E_{t}\left[A\left(S_{t+1}\right)^{+}\right]$,}

1990.01-2013.02

The table present results when the portfolio selection criterion is the maximization of the Sharpe ratio. $\mu$ is the mean and $\sigma_{O T-I T}$ is the volatility of the difference of the annualized percentage return between the OT and IT portfolios. Each tercile for the violation size corresponds to 92 observations. The $p$-values for the difference in means are derived via bootstrap with 10,000 draws. For the DD test, $10 \%$ trimming (deleting sequentially lowest outcomes in either return set) in the left and right tail is uniformly performed. Results for $5 \%$ trimming in the right tail are not shown since they are not qualitatively different than the results for $10 \%$ trimming on display.

\begin{tabular}{ccccccc}
\hline \multirow{2}{*}{ Variable } & \multicolumn{3}{c}{ Lowest Tercile } & \multicolumn{3}{c}{ Highest Tercile } \\
& 28-day & 14-day & 7-day & 28-day & 14-day & 7-day \\
\hline$\mu$ & -0.12 & 0.11 & 0.23 & 1.59 & 4.69 & 7.75 \\
$p$-value for $\mu \leq 0$ & 0.798 & 0 & 0 & 0.109 & 0.019 & 0.004 \\
$\sigma_{O T}$ & 15.03 & 10.35 & 13.75 & 16.78 & 19.23 & 20.34 \\
$\sigma_{I T}$ & 14.94 & 10.38 & 13.80 & 15.29 & 16.79 & 18.04 \\
$\sigma_{\text {OT-IT }}$ & 0.39 & 0.14 & 0.13 & 3.27 & 4.50 & 4.32 \\
DD test $p$-value & 1 & 0.070 & 0.058 & 0 & 0 & 0 \\
\hline
\end{tabular}




\section{Table 4: Relation between Stochastic Dominance and the Smile for 28-Day Option Portfolios, 1990.01-2013.02}

The portfolios are constructed 28 days prior to the options' maturity. We present results for four different portfolio selection criteria: the Sharpe ratio, gain/loss ratio, Sortino ratio, and the maximization of max $\hat{S} . \mu$ is the mean of the difference of the annualized percentage return between the OT and IT portfolios. Left (right) skew is 5\% OTM IV (5\% ITM IV) net of the ATM IV for a given cross-section. Each tercile for a given smile characteristic corresponds to 92 observations. The $p$-values for the difference in means are derived via bootstrap with 10,000 draws. For the DD test, $10 \%$ trimming (deleting sequentially lowest outcomes in either return set) in the left and right tail is uniformly performed. Results for 5\% trimming in the right tail are not shown since they are not qualitatively different than the results for $10 \%$ trimming on display.

\begin{tabular}{ccccccc}
\hline & \multicolumn{3}{c}{ Lowest Tercile } & \multicolumn{3}{c}{ Highest Tercile } \\
$\begin{array}{c}\text { Portfolio } \\
\text { selection } \\
\text { criterion }\end{array}$ & $\mu$ & $\begin{array}{c}p \text {-value } \\
\mu \leq 0\end{array}$ & $\begin{array}{l}\text { DD test } \\
\text {-value }\end{array}$ & $\mu$ & $\begin{array}{c}p \text {-value } \\
\mu \leq 0\end{array}$ & $\begin{array}{c}\text { DD test } \\
p \text {-value }\end{array}$ \\
\hline \multicolumn{7}{c}{ ATM IV } \\
\hline Sharpe ratio & -0.22 & 0.666 & 1 & 0.91 & 0.149 & 0 \\
Gain/loss ratio & 0.26 & 0.246 & 0.347 & 1.65 & 0.059 & 0 \\
Sortino ratio & -0.41 & 0.806 & 1 & 1.02 & 0.134 & 0 \\
max $\hat{S}$ & 0.01 & 0.486 & 0.587 & 1.17 & 0.109 & 0 \\
\hline & & & Left Skew & & & \\
\hline Sharpe ratio & 0.99 & 0.119 & 0.027 & -0.47 & 0.725 & 1 \\
Gain/loss ratio & 1.62 & 0.036 & 0.009 & -0.29 & 0.649 & 1 \\
Sortino ratio & 1.04 & 0.109 & 0.028 & -0.57 & 0.766 & 1 \\
max $\hat{S}$ & 1.24 & 0.070 & 0.016 & -0.48 & 0.748 & 1 \\
\hline & & & Right Skew & & & \\
\hline Sharpe ratio & 0.58 & 0.192 & 0.043 & -0.41 & 0.730 & 1 \\
Gain/loss ratio & 1.18 & 0.095 & 0.057 & 0.41 & 0.264 & 0.360 \\
Sortino ratio & 0.68 & 0.148 & 0.032 & -0.59 & 0.794 & 1 \\
max $\hat{S}$ & 0.84 & 0.100 & 0.006 & 0.05 & 0.430 & 0.444 \\
\hline
\end{tabular}




\section{Table 5: Relation between Stochastic Dominance and the Smile for 14-Day Option Portfolios, 1990.01-2013.02}

The portfolios are constructed 14 days prior to the options' maturity. We present results for four different portfolio selection criteria: the Sharpe ratio, gain/loss ratio, Sortino ratio, and the maximization of max $\hat{S} . \mu$ is the mean of the difference of the annualized percentage return between the OT and IT portfolios. Left (right) skew is 5\% OTM IV (5\% ITM IV) net of the ATM IV for a given cross-section. Each tercile for a given smile characteristic corresponds to 92 observations. The $p$-values for the difference in means are derived via bootstrap with 10,000 draws. For the DD test, $10 \%$ trimming (deleting sequentially lowest outcomes in either return set) in the left and right tail is uniformly performed. Results for 5\% trimming in the right tail are not shown since they are not qualitatively different than the results for $10 \%$ trimming on display.

\begin{tabular}{ccclccc}
\hline & \multicolumn{3}{c}{ Lowest Tercile } & \multicolumn{3}{c}{ Highest Tercile } \\
\hline $\begin{array}{c}\text { Portfolio } \\
\text { selection } \\
\text { criterion }\end{array}$ & $\mu$ & $\begin{array}{c}p \text {-value } \\
\mu \leq 0\end{array}$ & $\begin{array}{l}\text { DD test } \\
p \text {-value }\end{array}$ & $\mu$ & $\begin{array}{c}p \text {-value } \\
\mu \leq 0\end{array}$ & $\begin{array}{c}\text { DD test } \\
p \text {-value }\end{array}$ \\
\hline \multicolumn{7}{c}{ ATM IV } \\
\hline Sharpe ratio & 0.01 & 0.486 & 0.356 & 1.17 & 0.109 & 0.003 \\
Gain/loss ratio & 0.46 & 0.324 & 0.208 & 4.19 & 0.081 & 0.001 \\
Sortino ratio & 0.89 & 0.096 & 0.107 & 4.55 & 0.069 & 0 \\
max $\hat{S}$ & 0.03 & 0.453 & 0.327 & 4.06 & 0.085 & 0 \\
\hline & & & Left Skew & & & \\
\hline Sharpe ratio & 1.24 & 0.070 & 0.016 & -0.48 & 0.748 & 1 \\
Gain/loss ratio & 2.38 & 0.195 & 0.054 & 3.76 & 0.035 & 0.024 \\
Sortino ratio & 3.22 & 0.125 & 0.040 & 4.57 & 0.013 & 0.032 \\
max $\hat{S}$ & 1.94 & 0.221 & 0.052 & 3.80 & 0.032 & 0.026 \\
\hline & & & Right Skew & & & \\
\hline Sharpe ratio & 0.84 & 0.100 & 0.006 & 0.05 & 0.430 & 0.144 \\
Gain/loss ratio & 4.79 & 0.007 & 0 & -0.21 & 0.544 & 1 \\
Sortino ratio & 5.34 & 0.004 & 0.006 & -0.01 & 0.465 & 1 \\
max $\hat{S}$ & 4.65 & 0.010 & 0 & -0.61 & 0.666 & 1 \\
\hline
\end{tabular}




\section{Table 6: Relation between Stochastic Dominance and the Smile for Seven-Day Option Portfolios, 1990.01-2013.02}

The portfolios are constructed seven days prior to the options' maturity. We present results for four different portfolio selection criteria: the Sharpe ratio, gain/loss ratio, Sortino ratio, and the maximization of max $\hat{S} . \mu$ is the mean of the difference of the annualized percentage return between the OT and IT portfolios. Left (right) skew is 5\% OTM IV (5\% ITM IV) net of the ATM IV for a given cross-section. Each tercile for a given smile characteristic corresponds to 92 observations. The $p$-values for the difference in means are derived via bootstrap with 10,000 draws. For the DD test, $10 \%$ trimming (deleting sequentially lowest outcomes in either return set) in the left and right tail is uniformly performed. Results for 5\% trimming in the right tail are not shown since they are not qualitatively different than the results for $10 \%$ trimming on display.

\begin{tabular}{ccccccc}
\hline & \multicolumn{3}{c}{ Lowest Tercile } & \multicolumn{3}{c}{ Highest Tercile } \\
\hline $\begin{array}{c}\text { Portfolio } \\
\text { selection } \\
\text { criterion }\end{array}$ & $\mu$ & $\begin{array}{c}p \text {-value } \\
\mu \leq 0\end{array}$ & $\begin{array}{l}\text { DD test } \\
p \text {-value }\end{array}$ & $\mu$ & $\begin{array}{c}\text { p-value } \\
\mu \leq 0\end{array}$ & $\begin{array}{c}\text { DD test } \\
p \text {-value }\end{array}$ \\
\hline & \multicolumn{7}{c}{ ATM IV } \\
\hline Sharpe ratio & -1.33 & 0.715 & 1 & 3.97 & 0.033 & 0.001 \\
Gain/loss ratio & 0.79 & 0.176 & 0.154 & 4.77 & 0.033 & 0 \\
Sortino ratio & -0.87 & 0.627 & 1 & 4.27 & 0.027 & 0.001 \\
max $\hat{S}$ & 0.61 & 0.194 & 0.075 & 4.31 & 0.026 & 0.001 \\
\hline & & & Left Skew & & & \\
\hline Sharpe ratio & 1.68 & 0.239 & 0.296 & 1.79 & 0.233 & 0.184 \\
Gain/loss ratio & 2.85 & 0.117 & 0.063 & 3.43 & 0.013 & 0 \\
Sortino ratio & 2.00 & 0.208 & 0.308 & 2.29 & 0.172 & 0.134 \\
max $\hat{S}$ & 2.03 & 0.137 & 0.300 & 3.13 & 0.009 & 0 \\
\hline & & & Right Skew & & & \\
\hline Sharpe ratio & 5.13 & 0.007 & 0 & 1.33 & 0.219 & 0.354 \\
Gain/loss ratio & 6.01 & 0.008 & 0 & 2.07 & 0.008 & 0.001 \\
Sortino ratio & 5.41 & 0.006 & 0 & 1.41 & 0.215 & 0.343 \\
max $\hat{S}$ & 5.21 & 0.005 & 0 & 1.55 & 0.020 & 0.107 \\
\hline
\end{tabular}




\section{Table 7: Composition of Option Portfolios}

We present results for the Sharpe ratio portfolio selection criterion. We present results for the entire available sample period and before, after, and during the financial crisis. The total number of contracts in each category is the sum of the absolute values of the number of long and short contracts.

\begin{tabular}{|c|c|c|c|c|c|c|}
\hline $\begin{array}{l}\text { Option } \\
\text { Maturity } \\
\text { (days) }\end{array}$ & $\begin{array}{c}\text { Total \# } \\
\text { of call } \\
\text { contracts }\end{array}$ & $\begin{array}{c}\text { \# short } \\
\text { call } \\
\text { contracts }\end{array}$ & $\begin{array}{c}\text { \# long } \\
\text { call } \\
\text { contracts }\end{array}$ & $\begin{array}{c}\text { Total \# } \\
\text { of put } \\
\text { contracts }\end{array}$ & $\begin{array}{c}\text { \# short } \\
\text { put } \\
\text { contracts }\end{array}$ & $\begin{array}{c}\text { \# long } \\
\text { put } \\
\text { contracts }\end{array}$ \\
\hline \multicolumn{7}{|c|}{$1990.01-2013.02(\mathrm{~N}=278)$} \\
\hline 28 & 0.72 & 0.60 & 0.12 & 0.27 & 0.17 & 0.10 \\
\hline 14 & 0.79 & 0.69 & 0.10 & 0.18 & 0.10 & 0.08 \\
\hline 7 & 0.86 & 0.72 & 0.13 & 0.12 & 0.06 & 0.06 \\
\hline \multicolumn{7}{|c|}{$1990.01-2008.10(\mathrm{~N}=220)$} \\
\hline 28 & 0.79 & 0.65 & 0.14 & 0.21 & 0.11 & 0.10 \\
\hline 14 & 0.81 & 0.70 & 0.11 & 0.17 & 0.09 & 0.08 \\
\hline 7 & 0.87 & 0.73 & 0.14 & 0.12 & 0.06 & 0.06 \\
\hline \multicolumn{7}{|c|}{$2008.11-2009.10(\mathrm{~N}=12)$} \\
\hline 28 & 0.28 & 0.25 & 0.03 & 0.72 & 0.67 & 0.05 \\
\hline 14 & 0.47 & 0.41 & 0.06 & 0.44 & 0.36 & 0.09 \\
\hline 7 & 0.73 & 0.65 & 0.09 & 0.17 & 0.12 & 0.05 \\
\hline \multicolumn{7}{|c|}{ 2009.11-2013.02 (N = 46) } \\
\hline 28 & 0.50 & 0.46 & 0.04 & 0.44 & 0.32 & 0.12 \\
\hline 14 & 0.78 & 0.69 & 0.09 & 0.15 & 0.08 & 0.08 \\
\hline 7 & 0.83 & 0.71 & 0.12 & 0.08 & 0.04 & 0.04 \\
\hline
\end{tabular}




\section{Table 8: Frequency of 28-Day Options in the OT Portfolios}

We present the percentage of the months out of the total number of sample months in which $0,1,2$, or 3 types of options are included in the optimal zero-net-cost portfolio. For example, in the first row of the table, OTM short calls with two different strike-to-price ratio are included in 5.1\% of the sample months. ATM calls (puts) are included in the category of ITM calls (puts). We present results when the selection criterion is the Sharpe ratio.

\begin{tabular}{|c|c|c|c|c|c|}
\hline Option type & 0 & 1 & 2 & 3 & $>0$ \\
\hline \multicolumn{6}{|c|}{$1990.01-2013.02(\mathrm{~N}=278)$} \\
\hline Short calls OTM & 11.7 & 82.8 & 5.5 & 0 & 88.3 \\
\hline Short calls ITM & 69.2 & 28.6 & 2.2 & 0 & 30.8 \\
\hline Long calls OTM & 43.2 & 41.4 & 15.4 & 0 & 56.8 \\
\hline Long calls ITM & 93.4 & 6.6 & 0 & 0 & 6.6 \\
\hline Short puts OTM & 34.4 & 59.0 & 6.6 & 0 & 65.6 \\
\hline Short puts ITM & 89.7 & 9.9 & 0.4 & 0 & 10.3 \\
\hline Long puts OTM & 31.5 & 57.9 & 10.3 & 0.4 & 68.5 \\
\hline Long puts ITM & 78.0 & 21.6 & 0.4 & 0 & 22.0 \\
\hline \multicolumn{6}{|c|}{$1990.01-2008.10(\mathrm{~N}=220)$} \\
\hline Short calls OTM & 7.0 & 87.4 & 5.6 & 0 & 93.0 \\
\hline Short calls ITM & 71.6 & 26.0 & 2.3 & 0 & 28.4 \\
\hline Long calls OTM & 35.3 & 46.5 & 18.1 & 0 & 64.7 \\
\hline Long calls ITM & 91.6 & 8.4 & 0 & 0 & 8.4 \\
\hline Short puts OTM & 40.9 & 57.7 & 1.4 & 0 & 59.1 \\
\hline Short puts ITM & 87.4 & 12.1 & 0.5 & 0 & 12.6 \\
\hline Long puts OTM & 36.7 & 53.5 & 9.3 & 0.5 & 63.3 \\
\hline Long puts ITM & 80.9 & 18.6 & 0.5 & 0 & 19.1 \\
\hline \multicolumn{6}{|c|}{$2008.11-2009.10(\mathrm{~N}=12)$} \\
\hline Short calls OTM & 22.2 & 71.1 & 6.7 & 0 & 77.8 \\
\hline Short calls ITM & 55.6 & 42.2 & 2.2 & 0 & 44.4 \\
\hline Long calls OTM & 71.1 & 24.4 & 4.4 & 0 & 28.9 \\
\hline Long calls ITM & 100 & 0 & 0 & 0 & 0 \\
\hline Short puts OTM & 13.3 & 68.9 & 17.8 & 0 & 86.7 \\
\hline Short puts ITM & 97.8 & 2.2 & 0 & 0 & 2.2 \\
\hline Long puts OTM & 13.3 & 73.3 & 13.3 & 2.2 & 88.9 \\
\hline Long puts ITM & 77.8 & 22.2 & 0 & 0 & 22.2 \\
\hline \multicolumn{6}{|c|}{$2009.11-2013.02(\mathrm{~N}=46)$} \\
\hline Short calls OTM & 58.3 & 41.7 & 0 & 0 & 41.7 \\
\hline Short calls ITM & 75.0 & 25.0 & 0 & 0 & 25.0 \\
\hline Long calls OTM & 83.3 & 8.3 & 8.3 & 0 & 16.7 \\
\hline Long calls ITM & 100 & 0 & 0 & 0 & 0 \\
\hline Short puts OTM & 0 & 41.7 & 58.3 & 0 & 100 \\
\hline Short puts ITM & 100 & 0 & 0 & 0 & 0 \\
\hline Long puts OTM & 40.0 & 55.6 & 2.2 & 4.4 & 62.2 \\
\hline Long puts ITM & 77.8 & 22.2 & 0 & 0 & 22.2 \\
\hline
\end{tabular}




\section{Table 9: Characteristics of Calls in Relation to the Smile, 1990.01-2013.02}

We present results for the Sharpe ratio portfolio selection criterion. Left (right) skew is 5\% OTM IV (5\% ITM IV) net of the ATM IV for a given cross-section. The total number of contracts in each category is the sum of the absolute values of the number of long and short contracts. Each tercile for a given smile characteristic corresponds to 92 observations.

\begin{tabular}{|c|c|c|c|c|c|c|}
\hline \multicolumn{4}{|c|}{ Lowest Tercile } & \multicolumn{3}{|c|}{ Highest Tercile } \\
\hline $\begin{array}{l}\text { Option } \\
\text { Maturity } \\
\text { (days) }\end{array}$ & $\begin{array}{c}\text { Total \# } \\
\text { of } \\
\text { contracts } \\
\end{array}$ & $\begin{array}{c}\text { \# of } \\
\text { short } \\
\text { contracts }\end{array}$ & $\begin{array}{c}\text { \# of } \\
\text { long } \\
\text { contracts }\end{array}$ & $\begin{array}{c}\text { Total \# } \\
\text { of } \\
\text { contracts }\end{array}$ & $\begin{array}{c}\text { \# of } \\
\text { short } \\
\text { contracts }\end{array}$ & $\begin{array}{l}\text { \# of long } \\
\text { contracts }\end{array}$ \\
\hline \multicolumn{7}{|c|}{ ATM IV } \\
\hline 28 & 0.92 & 0.72 & 0.20 & 0.44 & 0.40 & 0.04 \\
\hline 14 & 0.90 & 0.78 & 0.12 & 0.64 & 0.57 & 0.06 \\
\hline 7 & 0.88 & 0.74 & 0.14 & 0.83 & 0.71 & 0.12 \\
\hline \multicolumn{7}{|c|}{ Left Skew } \\
\hline 28 & 0.79 & 0.65 & 0.14 & 0.64 & 0.52 & 0.11 \\
\hline 14 & 0.78 & 0.69 & 0.09 & 0.76 & 0.67 & 0.09 \\
\hline 7 & 0.89 & 0.74 & 0.15 & 0.82 & 0.69 & 0.13 \\
\hline \multicolumn{7}{|c|}{ Right Skew } \\
\hline 28 & 0.48 & 0.43 & 0.06 & 0.91 & 0.73 & 0.18 \\
\hline 14 & 0.63 & 0.57 & 0.06 & 0.92 & 0.79 & 0.14 \\
\hline 7 & 0.81 & 0.70 & 0.12 & 0.90 & 0.74 & 0.15 \\
\hline
\end{tabular}




\section{Table 10: Characteristics of Puts in Relation to the Smile, 1990.01-2013.02}

We present results for the Sharpe ratio portfolio selection criterion. Left (right) skew is 5\% OTM IV (5\% ITM IV) net of the ATM IV for a given cross-section. The total number of contracts in each category is the sum of the absolute values of the number of long and short contracts. Each tercile for a given smile characteristic corresponds to 92 observations.

\begin{tabular}{|c|c|c|c|c|c|c|}
\hline \multicolumn{4}{|c|}{ Lowest Tercile } & \multicolumn{3}{|c|}{ Highest Tercile } \\
\hline $\begin{array}{l}\text { Option } \\
\text { Maturity } \\
\text { (days) }\end{array}$ & $\begin{array}{c}\text { Total \# } \\
\text { of } \\
\text { contracts }\end{array}$ & $\begin{array}{c}\# \text { of } \\
\text { short } \\
\text { contracts }\end{array}$ & $\begin{array}{c}\# \text { of } \\
\text { long } \\
\text { contracts }\end{array}$ & $\begin{array}{c}\text { Total \# } \\
\text { of } \\
\text { contracts }\end{array}$ & $\begin{array}{c}\text { \# of } \\
\text { short } \\
\text { contracts }\end{array}$ & $\begin{array}{l}\text { \# of long } \\
\text { contracts }\end{array}$ \\
\hline \multicolumn{7}{|c|}{ ATM IV } \\
\hline 28 & 0.08 & 0.04 & 0.04 & 0.54 & 0.37 & 0.17 \\
\hline 14 & 0.10 & 0.05 & 0.05 & 0.29 & 0.16 & 0.13 \\
\hline 7 & 0.10 & 0.05 & 0.06 & 0.15 & 0.08 & 0.07 \\
\hline \multicolumn{7}{|c|}{ Left Skew } \\
\hline 28 & 0.20 & 0.12 & 0.08 & 0.35 & 0.24 & 0.12 \\
\hline 14 & 0.19 & 0.11 & 0.08 & 0.22 & 0.12 & 0.10 \\
\hline 7 & 0.08 & 0.04 & 0.03 & 0.14 & 0.07 & 0.08 \\
\hline \multicolumn{7}{|c|}{ Right Skew } \\
\hline 28 & 0.51 & 0.34 & 0.17 & 0.09 & 0.05 & 0.04 \\
\hline 14 & 0.29 & 0.17 & 0.13 & 0.08 & 0.04 & 0.04 \\
\hline 7 & 0.15 & 0.08 & 0.07 & 0.07 & 0.03 & 0.04 \\
\hline
\end{tabular}




\section{Table 11: Portfolio Returns and Stochastic Dominance Tests for "Second Pass" Options, 1990.01-2013.02}

We remove the options that are included in the "first pass" and repeat the search with the remaining options in the cross-section. We present results for four different portfolio selection criteria: the Sharpe ratio, gain/loss ratio, Sortino ratio, and the maximization of $\hat{S}$. Only the cross-sections with at least three calls and puts are admitted in the sample. $\mu_{O T}-\mu_{I T}$ is the mean and $\sigma_{O T-I T}$ is the volatility of the difference of the annualized percentage return between the OT and IT portfolios. In the top panel we present results for portfolios constructed 28 days to the option maturity; out of the 278 dates there are 265 dates with feasible portfolios. In the middle panel we present results for portfolios constructed 14 days to the option maturity; out of the 278 dates there are 265 dates with feasible portfolios. In the bottom panel we present results for portfolios constructed 7 days to the option maturity; out of the 278 dates there are 270 dates with feasible portfolios. The volatility of the return of the 28-day, 14-day, and seven-day IT portfolios is $16.48 \%, 17.15 \%$, and $18.12 \%$, respectively. Statistical test are performed on the basis of the total number of dates. The $p$-values for the difference in means are derived under via bootstrap with 10,000 draws. For the DD test, 10\% trimming (deleting sequentially lowest outcomes in either return set) in the left tail is uniformly performed while similar trimming in the right tail is as shown. The results of the DD tests without trimming in the right tail are not shown because they are qualitatively the same as the $p$-values for the difference in means.

\begin{tabular}{|c|c|c|c|c|c|c|}
\hline \multirow{2}{*}{$\begin{array}{l}\text { Portfolio } \\
\text { selection } \\
\text { criterion }\end{array}$} & \multirow{2}{*}{$\mu$} & \multirow{2}{*}{$\begin{array}{c}p \text {-value for } \\
\qquad \mu \leq 0\end{array}$} & \multirow{2}{*}{$\sigma_{O T}$} & \multirow[b]{2}{*}{$\sigma_{O T-I T}$} & \multicolumn{2}{|c|}{ DD test $p$-value } \\
\hline & & & & & $5 \%$ trim & $10 \%$ trim \\
\hline \multicolumn{7}{|c|}{ 28-Day Options } \\
\hline Sharpe ratio & 0.22 & 0.351 & 15.30 & 2.94 & 0.133 & 0.002 \\
\hline Gain/loss ratio & 0.22 & 0.353 & 15.30 & 2.94 & 0.132 & 0.002 \\
\hline Sortino ratio & 0.22 & 0.353 & 15.30 & 2.94 & 0.132 & 0.002 \\
\hline $\max \hat{S}$ & 0.17 & 0.372 & 15.30 & 2.93 & 0.152 & 0 \\
\hline \multicolumn{7}{|c|}{ 14-Day Options } \\
\hline Sharpe ratio & 1.28 & 0.131 & 15.38 & 3.57 & 0 & 0 \\
\hline Gain/loss ratio & 1.25 & 0.164 & 14.85 & 4.20 & 0 & 0 \\
\hline Sortino ratio & 1.15 & 0.158 & 15.37 & 3.59 & 0 & 0 \\
\hline $\max \hat{S}$ & 1.38 & 0.112 & 15.37 & 3.56 & 0 & 0 \\
\hline \multicolumn{7}{|c|}{ 7-Day Options } \\
\hline Sharpe ratio & 0.77 & 0.334 & 16.12 & 3.73 & 0.001 & 0.001 \\
\hline Gain/loss ratio & 1.22 & 0.254 & 15.71 & 4.32 & 0.003 & 0.005 \\
\hline Sortino ratio & 0.54 & 0.383 & 16.12 & 3.74 & 0.001 & 0.001 \\
\hline $\max \hat{S}$ & 0.76 & 0.329 & 16.13 & 3.68 & 0 & 0 \\
\hline
\end{tabular}




\section{Table 12: Regression Residuals of Options in the Optimal Portfolios, 1990.01-2013.02}

The table presents the means and $t$-stats of the residuals of the options that enter the optimal portfolios in units of the annualized IV in percentage points. For example, for short calls in the first line of the table, the mean residual 0.09 states that short calls in the optimal portfolio have, on average, annualized IV $0.09 \%$ above the skew. The standardized residuals are standardized each month by the standard deviation of the residuals in that month.

\begin{tabular}{|c|c|c|c|c|c|}
\hline \multirow[t]{2}{*}{ Option Type } & \multirow[t]{2}{*}{ \# Obs. } & \multicolumn{2}{|c|}{ Residuals } & \multicolumn{2}{|c|}{$\begin{array}{c}\text { Standardized } \\
\text { Residuals }\end{array}$} \\
\hline & & Mean & $t$-stat & Mean & $t$-stat \\
\hline \multicolumn{6}{|c|}{ 28-day Options } \\
\hline Short Call & 346 & 0.09 & 1.47 & -0.02 & -0.35 \\
\hline Long Call & 469 & -0.17 & -3.37 & -0.12 & -2.48 \\
\hline Short Put & 226 & 0.19 & 2.89 & 0.13 & 1.46 \\
\hline Long Put & 278 & -0.35 & -8.14 & -0.33 & -7.68 \\
\hline \multicolumn{6}{|c|}{ 14-day Options } \\
\hline Short Call & 371 & 0.07 & 1.38 & -0.04 & -0.52 \\
\hline Long Call & 482 & -0.18 & -3.85 & -0.27 & -3.76 \\
\hline Short Put & 203 & 0.17 & 2.74 & 0.17 & 1.38 \\
\hline Long Put & 225 & -0.32 & -5.74 & -0.35 & -5.78 \\
\hline \multicolumn{6}{|c|}{ 7-day Options } \\
\hline Short Call & 340 & 0.08 & 1.39 & -0.07 & -0.58 \\
\hline Long Call & 512 & -0.15 & -3.38 & -0.30 & -3.24 \\
\hline Short Put & 135 & 0.18 & 2.41 & 0.10 & 0.69 \\
\hline Long Put & 157 & -0.33 & -5.35 & -0.37 & -3.70 \\
\hline
\end{tabular}




\section{Table 13: Excess Returns Adjusted for Risk with the Three Fama-French Factors, 1990.01-}

2013.02

The excess returns of the OT options portfolio are adjusted for risk with the three factors in Fama and French (1993) by running the time-series regression $r_{O T, t}=\alpha+\beta_{M} r_{M, t}+\beta_{S M B} r_{S M B, t}+\beta_{H M L} r_{H M L, t}+\varepsilon_{t}$, where $r_{O T, t}, r_{M, t}, r_{S M B, t}$, and $r_{H M L, t}$ are the excess returns of the OT, market, small-minus-big, and high book-to-market minus low book-to-market portfolios in month $t$. Standard errors in parentheses, Newey-West (1987) corrected using four lags.

\begin{tabular}{cccc}
\hline$\alpha$ & $\beta_{M}$ & $\beta_{S M B}$ & $\beta_{H M L}$ \\
\hline 0.64 & -0.09 & -0.02 & -0.06 \\
$(0.07)$ & $(0.02)$ & $(0.01)$ & $(0.03)$ \\
\hline
\end{tabular}




\section{Table 14: Excess Returns Adjusted for Risk with the Constantinides, Jackwerth, and Savov (2013) Factors, 1990.01-2013.02}

The excess returns of the OT options portfolio are adjusted for market risk and one of the factors "Jump", "Volatility Jump", "Volatility", or "Liquidity" as $\overline{r_{O T, t}}-\beta_{M} \overline{r_{M, t}}-\beta_{f} \lambda_{f}$, where the risk prices of these factors, $\lambda_{\text {Jump }}, \lambda_{\text {VolJump }}, \lambda_{\text {Vol }}$, and $\lambda_{\text {Liq }}$ are estimated in Constantinides, Jackwerth, and Savov (2013) either from the universe of equities or from the universe of index options. Standard errors in parentheses, Newey-West (1987) corrected using four lags.

\begin{tabular}{cccc}
\hline Jump & Vol. Jump & Volatility & Liquidity \\
\hline \multicolumn{4}{c}{ Risk Premia Estimated from Equities } \\
\hline 0.75 & 0.41 & 0.67 & 0.65 \\
$(0.07)$ & $(0.07)$ & $(0.07)$ & $(0.07)$ \\
\hline \multicolumn{4}{c}{ Risk Premia Estimated from } \\
\hline 0.88 & 0.35 & 0.69 & 0.72 \\
$(0.07)$ & $(0.07)$ & $(0.07)$ & $(0.07)$ \\
\hline
\end{tabular}




\section{Table 15: Excess Returns Adjusted for Risk with the Christoffersen, Heston, and Jacobs (2013) Stochastic Discount Factor, 1990.01-2013.02}

The table displays in percent the average monthly excess return and the risk-adjusted excess return of the index and the OT portfolio. Confidence intervals on $t$-statistics are derived via a bootstrap procedure as in CHJ (2013, Table 2).

\begin{tabular}{|c|c|c|c|c|c|c|c|c|}
\hline \multirow[b]{2}{*}{$\begin{array}{l}\text { Option } \\
\text { maturity } \\
\text { (days) }\end{array}$} & \multicolumn{4}{|c|}{ Excess Return } & \multicolumn{4}{|c|}{ Risk Adjusted Excess Return } \\
\hline & $\mu$ & t-stat & $\begin{array}{c}\text {-stat } \\
95 \% \\
\text { LCI } \\
\end{array}$ & $\begin{array}{l}t \text {-stat } \\
95 \% \\
\text { UCI }\end{array}$ & $\mu$ & t-stat & $\begin{array}{c}t \text {-stat } \\
95 \% \text { LCI }\end{array}$ & $\begin{array}{c}t \text {-stat } \\
95 \% \mathrm{UCI}\end{array}$ \\
\hline & \multicolumn{8}{|c|}{ A: Index Returns } \\
\hline 28 & 0.78 & 2.68 & -1.89 & 2.05 & $-2.2 \mathrm{E}+07$ & -1.00 & -1.16 & $2.3 \mathrm{E}+05$ \\
\hline 21 & 0.93 & 2.72 & -1.83 & 2.11 & $-1.5 \mathrm{E}+07$ & -1.00 & -1.16 & $6.8 \mathrm{E}+05$ \\
\hline 14 & 0.93 & 2.17 & -1.90 & 2.03 & $-2.3 \mathrm{E}+04$ & -1.00 & -1.16 & $2.8 \mathrm{E}+03$ \\
\hline \multirow[t]{2}{*}{7} & 1.65 & 2.58 & -1.90 & 2.03 & $-1.9 \mathrm{E}+04$ & -1.00 & -1.16 & $1.5 \mathrm{E}+03$ \\
\hline & \multicolumn{8}{|c|}{ B: OT Portfolios } \\
\hline 28 & 5.53 & 2.06 & -2.53 & 1.65 & $5.8 \mathrm{E}+06$ & 1.00 & $-5.2 \mathrm{E}+04$ & 1.16 \\
\hline 21 & 7.40 & 4.74 & -2.52 & 1.70 & $2.1 \mathrm{E}+06$ & 1.00 & $-1.1 \mathrm{E}+05$ & 1.16 \\
\hline 14 & 6.77 & 2.63 & -1.56 & 2.66 & $1.3 \mathrm{E}+04$ & 1.01 & $-2.1 \mathrm{E}+02$ & 1.17 \\
\hline 7 & 18.00 & 1.23 & -5.47 & 1.34 & $2.1 \mathrm{E}+05$ & 1.00 & $-9.4 \mathrm{E}+03$ & 1.16 \\
\hline
\end{tabular}


Table 16: Frictionless Returns on Optimal Portfolios and Straddles, 1990.01-2013.02

The table displays in percent monthly frictionless average excess returns on OT portfolios and straddles as well as $95 \%$ bootstrap confidence intervals for market returns. The symbols ${ }^{*},{ }^{* *}$, and ${ }^{* * *}$ denote statistical significance at the $10 \%, 5 \%$, and $1 \%$ level via bootstrap with 10,000 draws. $p$-values for this test are consistent with bootstrapping $t$ statistics as in CHJ (2013, Table 2).

\begin{tabular}{ccccc}
\hline $\begin{array}{c}\text { Option } \\
\text { maturity } \\
\text { (days) }\end{array}$ & $\mu_{\text {MARKET }}$ & $\mu_{\text {MODEL }}$ & $95 \%$ LCI & $95 \%$ UCI \\
\hline \multicolumn{5}{c}{ OT Portfolios } \\
\hline 28 & $5.59^{* *}$ & $20.35^{* * *}$ & 0.64 & 11.13 \\
21 & $7.77^{* * *}$ & $20.55^{* * *}$ & 4.55 & 10.65 \\
14 & $7.36^{* * *}$ & $15.02^{* * *}$ & 1.20 & 11.37 \\
7 & $18.28^{*}$ & $43.91^{* * *}$ & -3.49 & 50.76 \\
\hline \multicolumn{5}{c}{ Straddles } \\
\hline 28 & $0.61^{* * *}$ & $2.08^{* *}$ & 0.23 & 0.95 \\
21 & $0.48^{* *}$ & $1.92^{* * *}$ & 0.04 & 0.87 \\
14 & $0.83^{* * *}$ & $1.99^{* * *}$ & 0.33 & 1.28 \\
7 & $1.38^{* * *}$ & $1.94^{* * *}$ & 0.65 & 2.12 \\
\hline
\end{tabular}




\section{Table 17: Portfolio Returns and Stochastic Dominance Tests for Three Indices, 2006.01- 2013.02}

The table presents results for the Sharpe ratio portfolio selection criterion. Monthly options for our 28-, 14-, and 7day results are available for 86 maturity dates. Weekly options for our weekly option results are available for 282 maturity dates. $\mu$ is the mean and $\sigma_{O T}\left(\sigma_{I T}\right)$ is the volatility of the OT (IT) portfolio and $\sigma_{O T-I T}$ is the volatility of the difference of the annualized percentage return between the OT and IT portfolios. The $p$-values for the difference in means are derived via bootstrap with 10,000 draws. For the DD test, 10\% trimming (deleting sequentially lowest outcomes in either return set) in the left tail is uniformly performed while similar trimming in the right tail is as shown. The results of the DD tests without trimming in the right tail are not shown because they are qualitatively the same as the $p$-values for the difference in means.

\begin{tabular}{|c|c|c|c|c|c|c|c|c|c|}
\hline \multirow{2}{*}{$\begin{array}{l}\text { Option } \\
\text { maturity } \\
\text { (days) }\end{array}$} & \multirow{2}{*}{$\begin{array}{c}\# \\
\text { Dates }\end{array}$} & \multirow{2}{*}{$\begin{array}{c}\# \\
\text { Feas. }\end{array}$} & \multirow{2}{*}{$\mu$} & \multirow{2}{*}{$\begin{array}{c}p \text {-value for } \\
\mu \leq 0\end{array}$} & \multirow{2}{*}{$\sigma_{O T}$} & \multirow{2}{*}{$\sigma_{I T}$} & \multirow{2}{*}{$\sigma_{O T-I T}$} & \multicolumn{2}{|c|}{ DD test $p$-value } \\
\hline & & & & & & & & $5 \%$ trim & $10 \%$ trim \\
\hline \multicolumn{10}{|c|}{ CAC Index } \\
\hline 28 & 82 & 74 & 1.05 & 0.315 & 18.47 & 20.88 & 5.67 & 0.235 & 0.180 \\
\hline 14 & 86 & 78 & 3.99 & 0.068 & 21.37 & 23.36 & 5.83 & 0.019 & 0 \\
\hline 7 & 84 & 76 & 5.07 & 0.023 & 22.06 & 23.36 & 4.81 & 0 & 0 \\
\hline \multicolumn{10}{|c|}{ DAX Index } \\
\hline 28 & 80 & 75 & 0.43 & 0.395 & 22.13 & 23.34 & 3.61 & 0.382 & 0.293 \\
\hline 14 & 79 & 65 & 1.94 & 0.073 & 23.41 & 24.59 & 2.37 & 0.041 & 0.008 \\
\hline 7 & 78 & 75 & 5.69 & 0.011 & 23.56 & 24.84 & 3.36 & 0.005 & 0.005 \\
\hline 7 (weekly) & 224 & 122 & 2.24 & 0.057 & 24.62 & 25.53 & 3.19 & 0.012 & 0.006 \\
\hline \multicolumn{10}{|c|}{ S\&P 500 Index } \\
\hline 28 & 86 & 84 & 0.22 & 0.302 & 20.07 & 20.62 & 1.75 & 0.197 & 0.107 \\
\hline 14 & 86 & 84 & 2.07 & 0.061 & 21.98 & 22.88 & 2.31 & 0.006 & 0.004 \\
\hline 7 & 86 & 85 & 6.17 & 0.002 & 19.13 & 20.23 & 3.18 & 0.009 & 0.001 \\
\hline 7 (weekly) & 257 & 227 & 1.94 & 0.027 & 20.23 & 20.80 & 2.25 & 0 & 0 \\
\hline
\end{tabular}




\section{Table 18: Portfolio Returns and Stochastic Dominance Tests in Relation to Volatility Forecast, 1990.01-2013.02}

The table presents results for the Sharpe ratio portfolio selection criterion. $\mu$ is the mean and $\sigma_{O T-I T}$ is the volatility of the difference of the annualized percentage return between the OT and IT portfolios. The volatility of the return of the 28-day, 14-day, and seven-day IT portfolios is $16.48 \%, 17.15 \%$, and $18.12 \%$, respectively. Statistical tests are performed on the basis of the total number of dates. The $p$-values for the difference in means are derived under via bootstrap with 10,000 draws. For the DD test, 10\% trimming (deleting sequentially lowest outcomes in either return set) in the left tail is uniformly performed while similar trimming in the right tail is as shown. The results of the DD tests without trimming in the right tail are not shown because they are qualitatively the same as the $p$-values for the difference in means.

\begin{tabular}{|c|c|c|c|c|c|c|c|}
\hline \multirow{2}{*}{$\begin{array}{l}\text { Option } \\
\text { maturity } \\
\text { (days) }\end{array}$} & \multirow{2}{*}{$\begin{array}{c}\text { \# Feasible } \\
\text { dates }\end{array}$} & \multirow{2}{*}{$\mu$} & \multirow{2}{*}{$\begin{array}{c}p \text {-value } \\
\text { for } \mu \leq 0\end{array}$} & \multirow{2}{*}{$\sigma_{O T}$} & \multirow{2}{*}{$\sigma_{O T-I T}$} & \multicolumn{2}{|c|}{ DD test $p$-value } \\
\hline & & & & & & $5 \%$ trim & $10 \%$ trim \\
\hline \multicolumn{8}{|c|}{ A: GJR } \\
\hline 28 & 218 & 0.45 & 0.170 & 15.50 & 2.57 & 0.029 & 0 \\
\hline 14 & 215 & 1.23 & 0.019 & 16.34 & 1.91 & 0 & 0 \\
\hline 7 & 222 & 1.53 & 0.082 & 17.04 & 2.60 & 0 & 0 \\
\hline \multicolumn{8}{|c|}{ B: EGARCH } \\
\hline 28 & 224 & 0.32 & 0.235 & 15.79 & 2.11 & 0.125 & 0.007 \\
\hline 14 & 225 & 1.25 & 0.018 & 16.39 & 1.92 & 0 & 0 \\
\hline 7 & 222 & 2.08 & 0.053 & 17.11 & 2.85 & 0 & 0 \\
\hline \multicolumn{8}{|c|}{ C: Random Walk } \\
\hline 28 & 243 & -0.30 & 0.682 & 15.38 & 2.85 & 1 & 1 \\
\hline 14 & 235 & 1.27 & 0.005 & 16.61 & 1.51 & 0.010 & 0 \\
\hline 7 & 239 & 0.93 & 0.176 & 17.33 & 2.25 & 0 & 0 \\
\hline
\end{tabular}




\section{Table 19: Portfolio Returns and Stochastic Dominance Tests for Different Risk Premia, 1990.01-2013.02}

The table presents results when the assumed annual risk premium is $2 \%$ and $6 \%$ for the Sharpe ratio selection criterion. $\mu$ is the mean and $\sigma_{O T-I T}$ is the volatility of the difference of the annualized percentage return between the OT and IT portfolios. The volatility of the return of the 28-day, 14-day, and seven-day IT portfolios is $16.48 \%, 17.15 \%$, and $18.12 \%$, respectively. Statistical test are performed on the basis of the total number of dates. The $p$-values for the difference in means are derived under via bootstrap with 10,000 draws. For the DD test, 10\% trimming (deleting sequentially lowest outcomes in either return set) in the left tail is uniformly performed while similar trimming in the right tail is as shown. The results of the DD tests without trimming in the right tail are not shown because they are qualitatively the same as the $p$-values for the difference in means.

\begin{tabular}{|c|c|c|c|c|c|c|c|}
\hline \multirow{2}{*}{$\begin{array}{l}\text { Option } \\
\text { maturity } \\
\text { (days) }\end{array}$} & \multirow{2}{*}{$\begin{array}{c}\text { \# Feasible } \\
\text { dates }\end{array}$} & \multirow{2}{*}{$\mu$} & \multirow{2}{*}{$\begin{array}{c}p \text {-value for } \\
\mu \leq 0\end{array}$} & \multirow{2}{*}{$\sigma_{\text {OT }}$} & \multirow{2}{*}{$\sigma_{O T-I T}$} & \multicolumn{2}{|c|}{ DD test $p$-value } \\
\hline & & & & & & $5 \%$ trim & $10 \%$ trim \\
\hline & \multicolumn{7}{|c|}{ Risk Premium 2\% } \\
\hline 28 & 272 & 0.40 & 0.158 & 15.78 & 2.03 & 0.090 & 0 \\
\hline 14 & 271 & 0.95 & 0.066 & 16.28 & 2.04 & 0.017 & 0 \\
\hline \multirow[t]{2}{*}{7} & 270 & 2.66 & 0.002 & 17.27 & 2.16 & 0.005 & 0.005 \\
\hline & \multicolumn{7}{|c|}{ Risk Premium 6\% } \\
\hline 28 & 268 & 0.57 & 0.121 & 15.62 & 2.37 & 0.129 & 0 \\
\hline 14 & 266 & 1.96 & 0.025 & 16.28 & 2.15 & 0 & 0 \\
\hline 7 & 269 & 2.42 & 0.000 & 17.28 & 2.11 & 0 & 0 \\
\hline
\end{tabular}




\section{Table 20: Trading Results with Restricted Option Choices, 1990.01-2013.02}

The first panel presents results when we exclude calls that violate the Constantinides-Perrakis (2002) upper bound. The second panel presents results when puts are excluded. The third panel presents results when calls are excluded. $\mu$ is the mean and $\sigma_{O T-I T}$ is the volatility of the difference of the annualized percentage return between the OT and IT portfolios. Statistical test are performed on the basis of the total number of dates. The $p$-values for the difference in means are derived under via bootstrap with 10,000 draws. For the DD test, 10\% trimming (deleting sequentially lowest outcomes in either return set) in the left tail is uniformly performed while similar trimming in the right tail is as shown. The results of the DD tests without trimming in the right tail are not shown because they are qualitatively the same as the $p$-values for the difference in means.

\begin{tabular}{|c|c|c|c|c|c|c|}
\hline \multirow{2}{*}{$\begin{array}{l}\text { Option } \\
\text { maturity } \\
\text { (days) }\end{array}$} & \multirow{2}{*}{$\mu$} & \multirow{2}{*}{$\begin{array}{c}p \text {-value for } \\
\quad \mu \leq 0\end{array}$} & \multirow[b]{2}{*}{$\sigma_{O T}$} & \multirow[b]{2}{*}{$\sigma_{O T-I T}$} & \multicolumn{2}{|c|}{ DD test $p$-value } \\
\hline & & & & & $5 \%$ trim & $10 \%$ trim \\
\hline \multicolumn{7}{|c|}{ Optimal Portfolios ex Call Upper Bound Violations } \\
\hline 28 & 0.04 & 0.458 & 15.81 & 1.88 & 0.241 & 0.003 \\
\hline 14 & 0.70 & 0.175 & 16.13 & 2.46 & 0.009 & 0 \\
\hline 7 & 1.31 & 0.096 & 17.15 & 2.39 & 0 & 0 \\
\hline \multicolumn{7}{|c|}{ Optimal Portfolios Composed of Calls } \\
\hline 28 & -0.10 & 0.531 & 14.79 & 4.84 & 1 & 1 \\
\hline 14 & 0.93 & 0.295 & 14.71 & 6.00 & 0.007 & 0.007 \\
\hline 7 & 1.33 & 0.298 & 16.17 & 6.06 & 0.005 & 0 \\
\hline \multicolumn{7}{|c|}{ Optimal Portfolios Composed of Puts } \\
\hline 28 & -0.24 & 0.843 & 16.31 & 0.98 & 1 & 1 \\
\hline 14 & -0.27 & 0.797 & 16.83 & 1.24 & 1 & 1 \\
\hline 7 & -0.22 & 0.764 & 17.90 & 1.30 & 1 & 1 \\
\hline
\end{tabular}




\section{Table 21: Frictionless Portfolio Returns and Stochastic Dominance Tests, 1990.01-2013.02}

The table presents results for the Sharpe ratio portfolio selection criterion. $\mu$ is the mean and $\sigma_{0 T-I T}$ is the volatility of the difference of the annualized percentage return between the OT and IT portfolios. In the top panel we present results for portfolios constructed under costless trading in the index and options; for all dates there are feasible portfolios. The volatility of the return of the 28-day, 14-day, and seven-day IT portfolios is $16.48 \%, 17.15 \%$, and $18.12 \%$, respectively. Statistical test are performed on the basis of the total number of dates. The $p$-values for the difference in means are derived under via bootstrap with 10,000 draws. For the DD test, $10 \%$ trimming (deleting sequentially lowest outcomes in either return set) in the left tail is uniformly performed while similar trimming in the right tail is as shown. The results of the DD tests without trimming in the right tail are not shown because they are qualitatively the same as the $p$-values for the difference in means. In the bottom panel, we present results for these portfolios' composition. We present results for the entire available sample. The total number of contracts in each category is the sum of the absolute values of the number of long and short contracts.

\begin{tabular}{|c|c|c|c|c|c|c|c|}
\hline \multirow[b]{3}{*}{$\begin{array}{l}\text { Option } \\
\text { maturity } \\
\text { (days) }\end{array}$} & \multicolumn{7}{|c|}{ Costless Trading in the Index and Options } \\
\hline & \multirow[b]{2}{*}{$\mu$} & \multirow[b]{2}{*}{$\begin{array}{c}p \text {-value for } \\
\mu \leq 0\end{array}$} & \multirow[b]{2}{*}{$\sigma_{O T}$} & \multirow[b]{2}{*}{$\sigma_{O T-I T}$} & & \multicolumn{2}{|c|}{ DD test $p$-value } \\
\hline & & & & & & $5 \%$ trim & $10 \%$ trim \\
\hline 28 & 0.41 & 0 & 16.39 & 0.49 & & 0 & 0 \\
\hline 14 & 0.63 & 0 & 16.97 & 0.43 & & 0 & 0 \\
\hline 7 & 0.88 & 0 & 17.96 & 0.38 & & 0 & 0 \\
\hline \multicolumn{8}{|c|}{ Portfolio Composition for Costless Trading in the Index and Options } \\
\hline & $\begin{array}{l}\text { Total \# of } \\
\text { calls }\end{array}$ & $\begin{array}{c}\text { \# short call } \\
\text { contracts }\end{array}$ & $\begin{array}{l}\text { \# long } \\
\text { call } \\
\text { contracts }\end{array}$ & $\begin{array}{l}\text { Total \# of } \\
\text { puts }\end{array}$ & $\begin{array}{l}\text { \# short } \\
\text { put } \\
\text { contracts }\end{array}$ & $\begin{array}{l}\text { \# long put } \\
\text { contracts }\end{array}$ & $\begin{array}{c}\text { \# short } \\
\text { index }\end{array}$ \\
\hline 28 & 0.46 & 0.10 & 0.36 & 0.50 & 0.43 & 0.07 & 0.36 \\
\hline 14 & 0.49 & 0.10 & 0.39 & 0.51 & 0.48 & 0.03 & 0.45 \\
\hline 7 & 0.50 & 0.12 & 0.37 & 0.50 & 0.49 & 0.01 & 0.37 \\
\hline
\end{tabular}



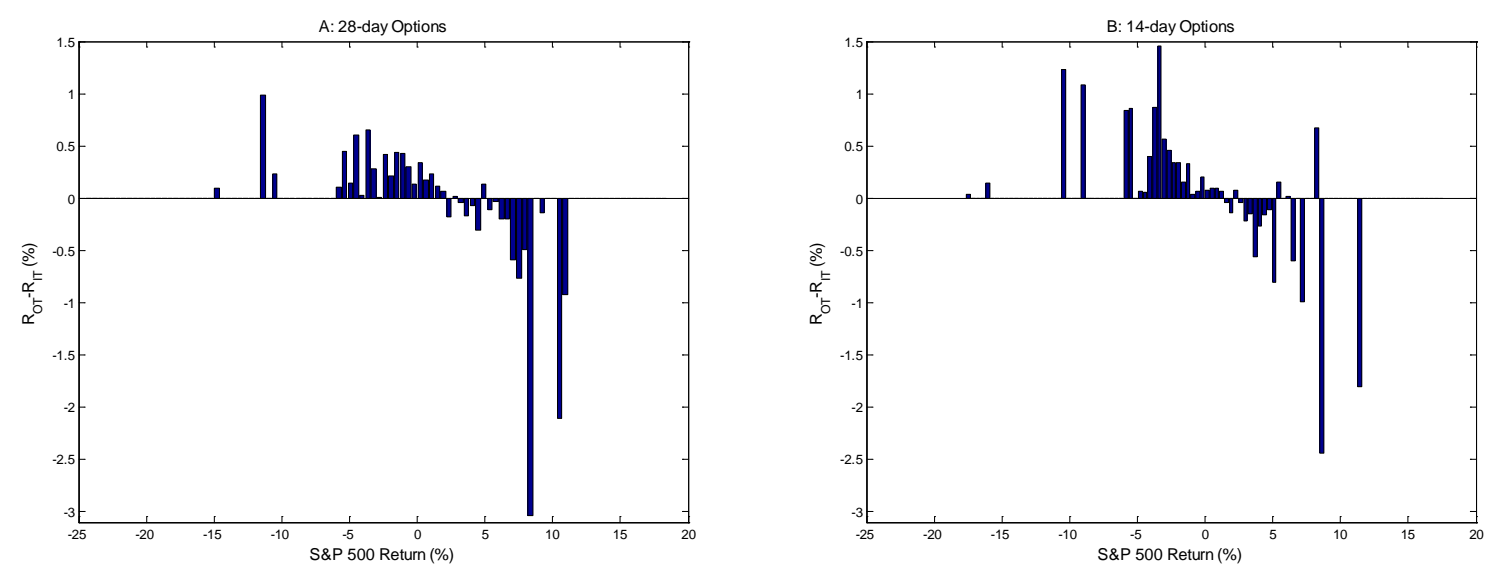

Figure 1: Difference in the Realized Returns between the OT and IT 28-day Portfolios

The returns are measured in the 278 28-day and 14-day periods over 1990.01-2013.02 and sorted by the contemporaneous S\&P 500 returns. Bars in the graph correspond to means for 100 equally spaced S\&P returns. Consistent with the objective of constructing OT portfolios that stochastically dominate the IT portfolios, the difference in returns is generally decreasing in the S\&P 500 index return.
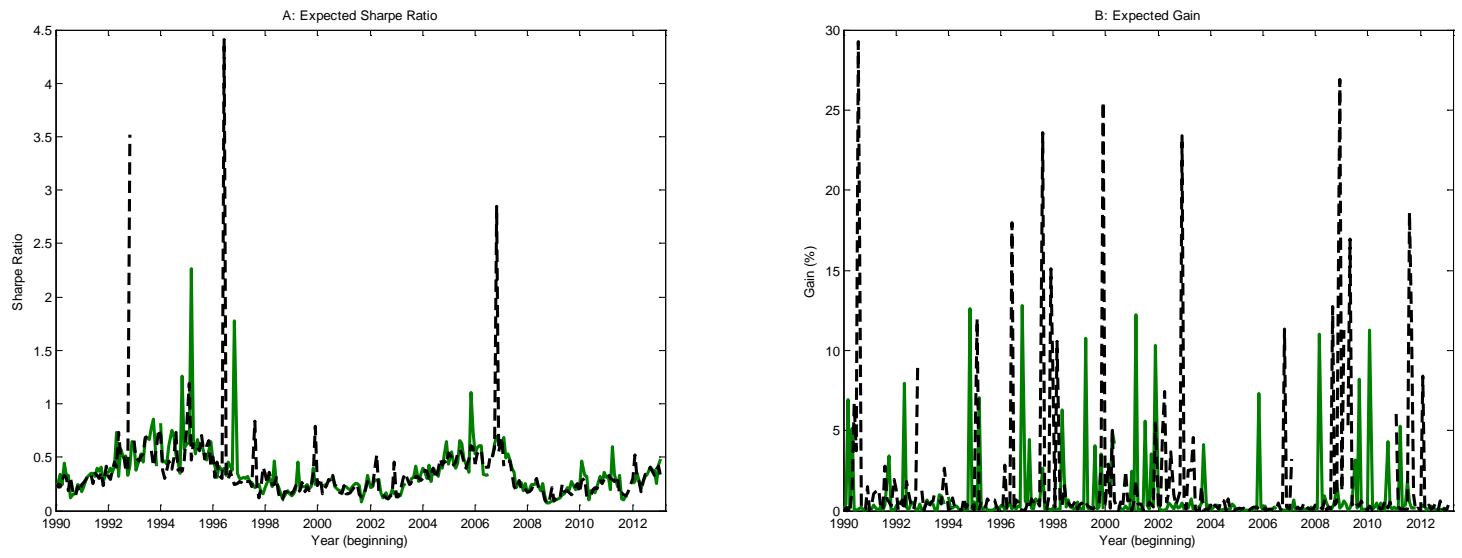

Figure 2: Time Series of Maximized Sharpe Ratio and Expected Gain

The figure displays the time series for expected Sharpe ratio and the corresponding expected gain. The solid lighter line corresponds to 28-day options and the dashed darker line corresponds to 14-day options. 